\title{
Thermal Degradation Mechanisms of Polybenzoxazines
}

\author{
Jale Hacaloğlu, ${ }^{*, 1}$ Tamer Uyar, $^{\dagger}$ and Hatsuo Ishida \\ * Department of Chemistry, Middle East Technical University, Ankara, 06531, Turkey \\ ${ }^{\dagger}$ UNAM-Institute of Materials Science and Nanotechnology, Bilkent University, Ankara, 06800, Turkey \\ ${ }^{\star}$ Department of Macromolecular Science and Engineering, Case Western Reserve University, Cleveland, Ohio, 44106, USA \\ ${ }^{1}$ Corresponding author: E-mail: jale@metu.edu.tr
}

\section{INTRODUCTION}

Among the several techniques used to investigate the thermal characteristics of polymers, thermogravimetric analyzer (TGA), TGA interfaced with Fourier transform infrared spectroscopy (FTIR) or gas chromatography-mass spectrometry (GC-MS), and pyrolysis techniques coupled with FTIR, GC-MS, and MS provide information on thermal degradation products [1-11]. FTIR combined with TGA or a pyrolysis technique provides information about the type and functionality of the degradation products as a function of time and/or temperature [1,2]. Yet, information on neither the exact structure of all the decomposition products nor the separation of different decomposition products coming off at the same time can be provided. The use of GC-MS instead of FTIR allows the separation and identification of degradation products [4,7]. However, condensation of high mass pyrolysates and reactions between the decomposition products during the transport of degradation products from TGA or pyrolyzer system to FTIR or GC-MS are highly probable. With the direct pyrolysis-mass spectrometry (DP-MS) technique, secondary condensation reactions are eliminated and the detection of primary degradation products, high mass pyrolysates, and unstable thermal degradation products becomes possible as a consequence of removal of the thermal degradation products rapidly from the heating zone by the high vacuum system and rapid detection system [10,11]. Thus, a better understanding of the thermal characteristics, polymerization, and cross-linking processes can be achieved.

The thermal degradation processes of various polybenzoxazines were studied, and the degradation mechanisms were proposed in the literature [12-22]. The structural effects of phenols and amines on the thermal degradation of polybenzoxazines were investigated systematically
[12-17,20]. The thermal decomposition studies of polybenzoxazines are sometimes difficult because a large number of degradation products are released during the pyrolysis of polybenzoxazines; therefore, model dimers and oligomers of polybenzoxazines were also examined in order to have a clear understanding of the thermal degradation mechanisms of polybenzoxazines [12,18,19,21]. Here, the findings related to the thermal degradation processes of polybenzoxazines and the proposed degradation mechanisms for polybenzoxazines are summarized.

\section{THERMAL CHARACTERISTICS OF POLYBENZOXAZINES}

Benzoxazines polymerize via a thermally activated cationic ring-opening reaction to form a phenolic structure characterized by a Mannich-based bridge $\left(-\mathrm{CH}_{2}-\mathrm{NR}-\mathrm{CH}_{2}-\right)$, as shown in Scheme 1. The chemical structures of the most common benzoxazines such as phenol-methylamine-based (Ph-m), phenol-aniline-based (Ph-a), bisphenol A-methylamine-based (BA-m), and bisphenol A-aniline-based (BA-a) benzoxazines are given in Scheme 2. The thermal degradation processes of polybenzoxazines were studied by TGA, TGA interfaced with a Fourier transform infrared spectrometer (TGA-FTIR), evolved gas analysis (EGA) performed by GC-MS, and DP-MS [12-22].

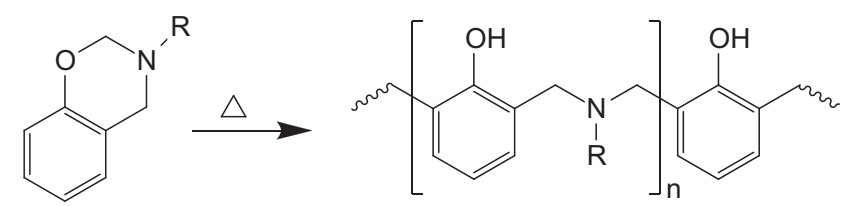

SCHEME 1 Benzoxazine polymerization. 


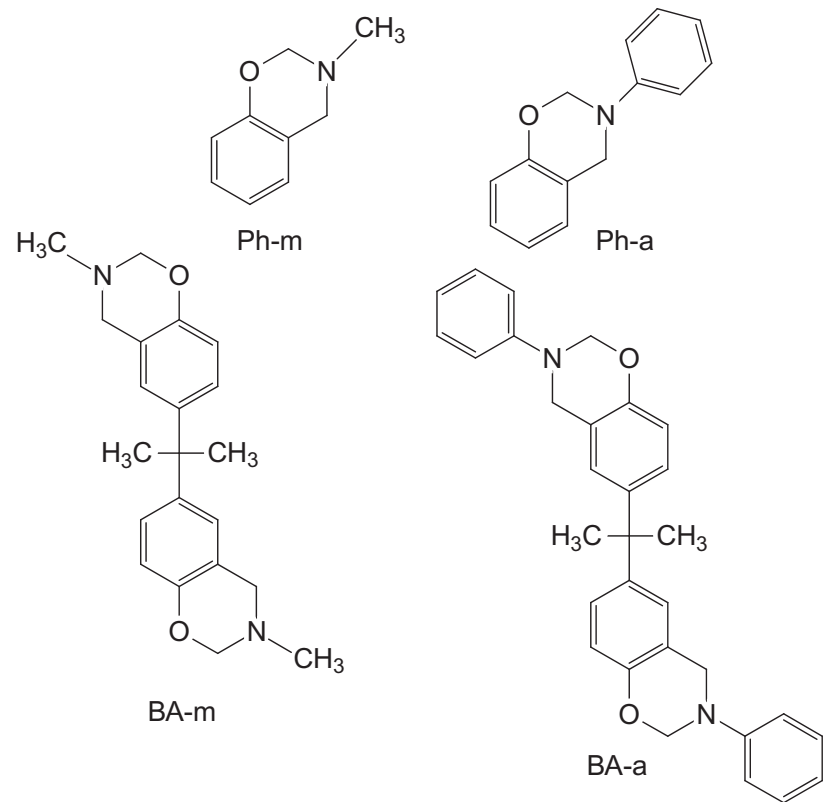

SCHEME 2 The chemical structures of phenol-methyl-based (Ph-m), phenol-aniline-based (Ph-a), bisphenol A-methyl-based (BA-m), bisphenol A-aniline-based (BA-a) benzoxazine monomers.

\subsection{Thermogravimetric Analysis of Polybenzoxazines}

The TGA thermograms of $\operatorname{poly}(\mathbf{P h}-\mathbf{m})$, poly(Ph-a), poly (BA-m), and poly(BA-a) are given in Figures 1-4, respectively. The TGA thermograms show that more than one degradation step occurs during the thermal degradation of polybenzoxazines. In TGA thermograms, polybenzoxazines show an initial weight loss starting around $260-280{ }^{\circ} \mathrm{C}$ and the main degradation occurs between 300 and $450{ }^{\circ} \mathrm{C}$ depending on the molecular structure of polybenzoxazines [12,13,20]. As can be seen from the derivative of weight loss of polybenzoxazines in Figure 1-4, multiple weight loss events occur during the heating from room temperature to $800{ }^{\circ} \mathrm{C}$. The initial weight loss at the low temperature region (around $260-280^{\circ} \mathrm{C}$ ) is due to the evaporation of amines and the major weight loss at temperatures between 300 and $450{ }^{\circ} \mathrm{C}$ is due to the degradation of the phenolic moieties. These findings are supported by evolved gas analyses (EGAs) by FTIR and GC-MS because TGA by itself does not provide enough information about the thermal degradation products of polybenzoxazines $[12,13,20]$. Hence, evolved gas analyses (EGA) need to be carried out by FTIR and GC-MS in order to investigate the degradation products and the thermal degradation mechanism of polybenzoxazines.

\subsection{Evolved Gas Analyses (EGA) of Polybenzoxazines by FTIR}

The FTIR evolved gas analysis (EGA) for aromatic aminebased and aliphatic amine-based polybenzoxazines has been carried out $[12,13]$. It is worth mentioning that exact identification of the degraded products is difficult from the FTIR spectra alone, because the FTIR spectra are of mixtures of the degraded compounds; however, certain characteristic absorption bands are good enough for the classification of the particular species. The FTIR evolved gas analyses (EGA) of polybenzoxazines were divided into three sections: (1) the initial degradation stage starting

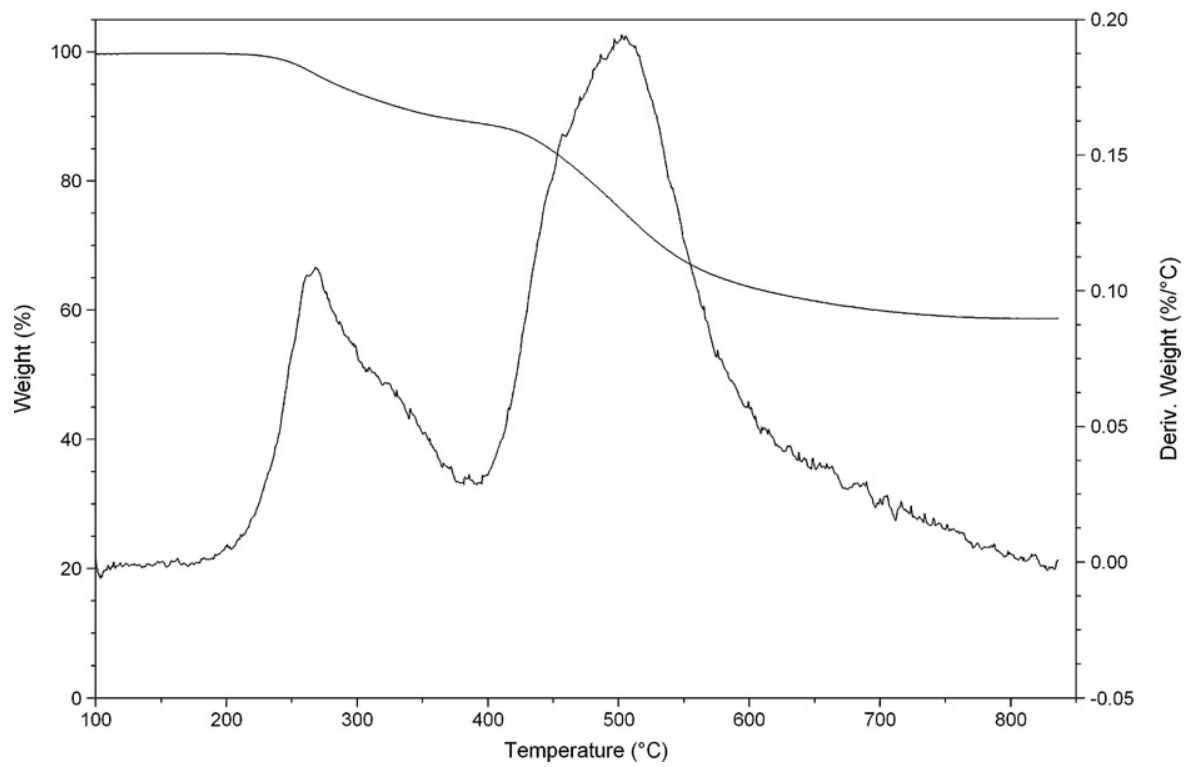

FIGURE 1 TGA thermogram and its derivative from the degradation of poly(Ph-m) under nitrogen. 


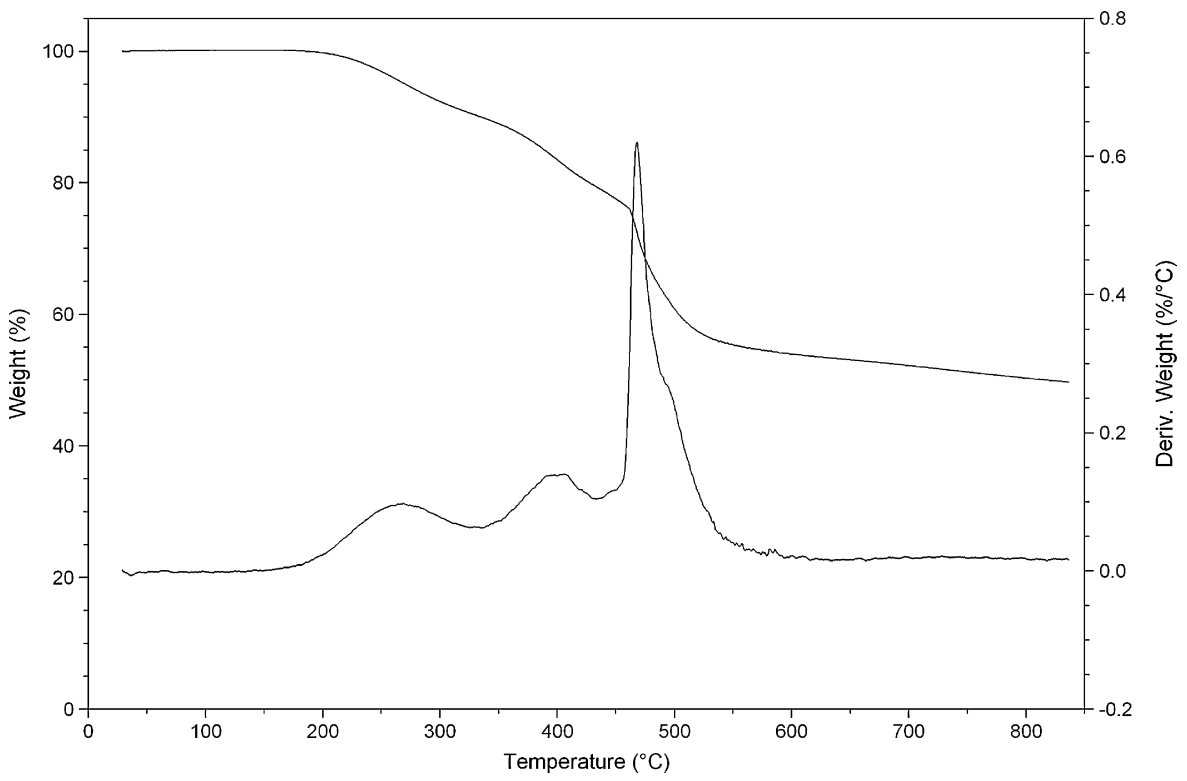

FIGURE 2 TGA thermogram and its derivative from the degradation of poly(Ph-a) under nitrogen.

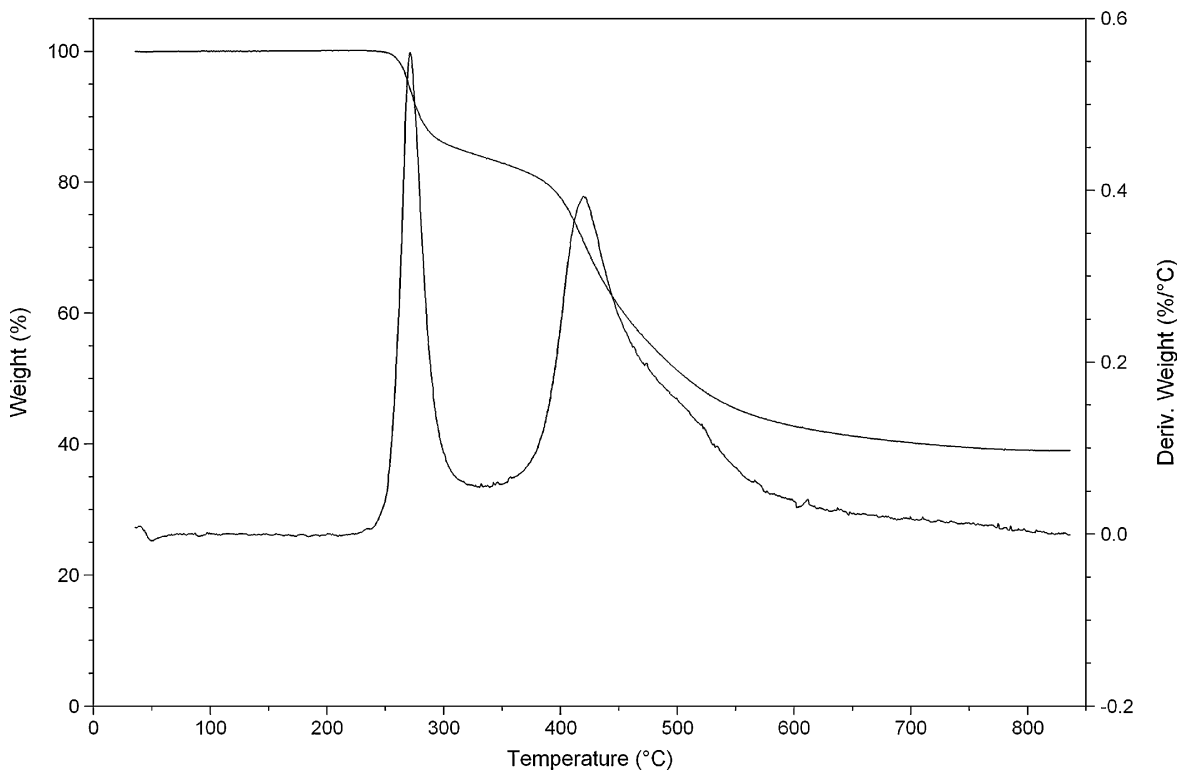

FIGURE 3 TGA thermogram and its derivative from the degradation of poly(BA-m) under nitrogen.

from room temperature to $300{ }^{\circ} \mathrm{C}$, (2) the intermediate degradation stage between 300 and $400{ }^{\circ} \mathrm{C}$, and (3) the final degradation stage, which occurs above $400{ }^{\circ} \mathrm{C}$. In the case of aliphatic amine-based polybenzoxazines, the initial degradation products were aliphatic amines while aniline was a major degradation product in aromatic amine-based polybenzoxazines. At the intermediate degradation stage, substituted phenols were evolved. At the final degradation stage, which occurred above $400{ }^{\circ} \mathrm{C}$, only phenols were detected.
Low and Ishida have carried out systematic FTIR evolved gas analyses for aliphatic amine-based polybenzoxazines, namely, bisphenol A methylaminebased (BA-m), bisphenol A ethylamine-based (BA-e), bisphenol A $n$-propylamine-based (BA-np), and bisphenol A amylamine-based (BA-amyl) polybenzoxazines [12]. For all aliphatic amine-based polybenzoxazine compounds, aliphatic amines were detected at the initial degradation stage (below $300{ }^{\circ} \mathrm{C}$ ). It was observed that the initial degradation step for $\operatorname{poly}(\mathbf{B A}-\mathbf{m})$ and $\operatorname{poly}(\mathbf{B A}-\mathbf{e})$ differed 


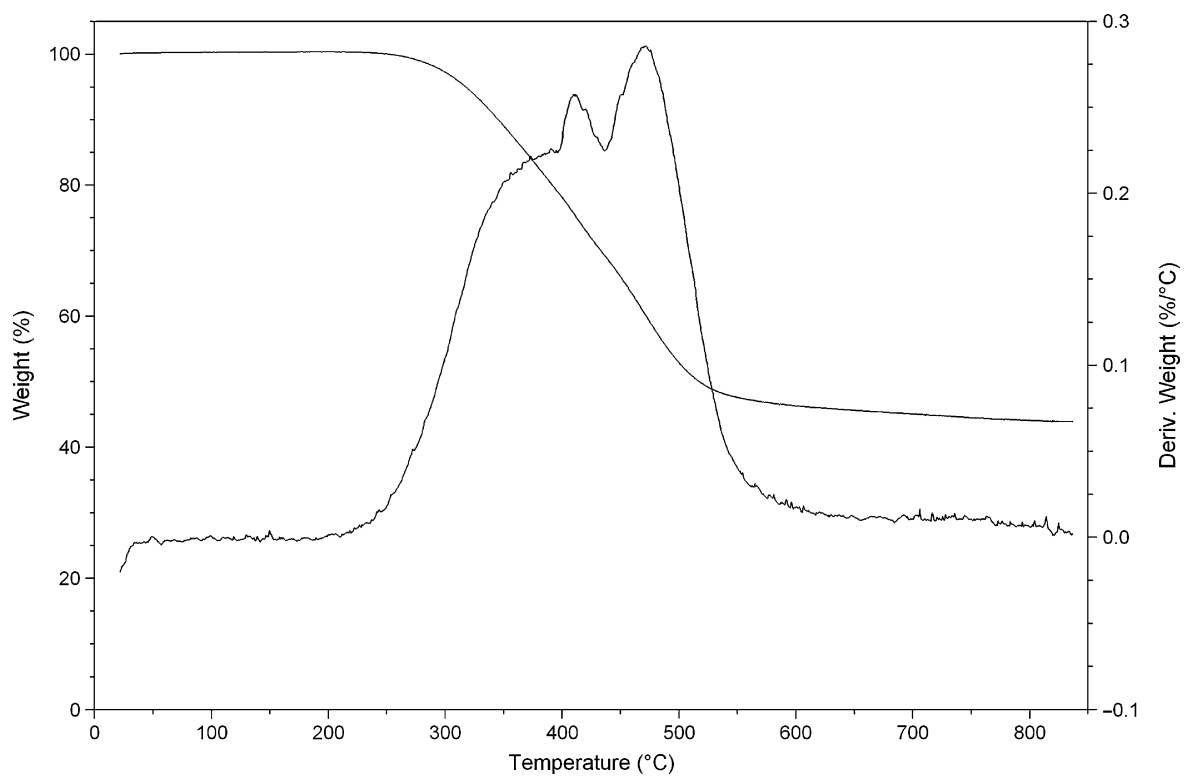

FIGURE 4 TGA thermogram and its derivative from the degradation of poly(BA-a) under nitrogen.

significantly from that for $\operatorname{poly}(\mathbf{B A}-\mathbf{n p})$ and poly(BA-amyl). The initial degradation products were dimethylamine and methylethylamine for poly(BA-m) and poly(BA-e), respectively. In the case of poly(BA-np) and poly(BA-amyl), the release of ammonia was detected, which indicates that the Mannich base and the substituent attached to the nitrogen must have cleaved. In addition, the release of various amines, possibly secondary or tertiary amines, were also detected at the initial degradation stage. Comparison of the spectra obtained from the initial degradation step of polybenzoxazines with the vapor-phase spectra of methylamine, ethylamine, propylamine, and amylamine confirmed that primary amines are not major degradation components for these aliphatic amine-based polybenzoxazines. For poly(BA-m), a strong band at $1670 \mathrm{~cm}^{-1}$ was detected at around $280{ }^{\circ} \mathrm{C}$, which was assigned to a free Schiff base $(\mathrm{C}=\mathrm{N})$. At this initial stage, no aromatic band was detected in the FTIR spectrum; thus, aliphatic species and aliphatic Schiff bases are most likely the decomposition products. In the case of poly (BA-e), poly(BA-np), and poly(BA-amyl), the observed Schiff base band was not as strong as in poly(BA-m), indicating that the concentration of the Schiff base may be dependent on the type of amine substituent.

At the intermediate degradation stage (between 300 and $400{ }^{\circ} \mathrm{C}$ ) of aliphatic amine-based polybenzoxazines, no aliphatic amine absorption bands were observed in the FTIR spectra of evolved gas analyses (EGA), indicating that the amines that evaporated very likely come from the amines that are part of the branches and chain ends. In addition, the concentration of the Schiff base was also decreased at this stage. At around $400{ }^{\circ} \mathrm{C}$, a sharp peak at $3650 \mathrm{~cm}^{-1}$ was detected in the FTIR spectra of all the aliphatic amine-based polybenzoxazines. This band is due to the free
$\mathrm{OH}$ stretching. In addition, substituted benzene modes at 1600,1480 , and $747 \mathrm{~cm}^{-1}$ were also detected in the spectra. These findings suggested that substituted phenols are the degradation products at this stage. The type of substituted phenols is difficult to identify by FTIR spectra alone, yet possible candidates would be phenol, $p$-cresol, $o$-cresol, dimethylphenol, trimethylphenol, isopropyl-phenol, etc. Above $400{ }^{\circ} \mathrm{C}$, the recorded FTIR spectra of the evolved gas of degraded polybenzoxazines were similar to each other. It was observed that the characteristic band of the aliphatic amine had disappeared totally and only various substituted phenols were detected.

The FTIR evolved gas analyses for aromatic aminebased polybenzoxazines were also studied [13]. In this case, aniline was the major degradation product at the initial degradation stage. The evaporation of amine is a consequence of the Mannich base cleavage. The Schiff base was also detected as a degradation product for aromatic amine-based polybenzoxazines. At around $400{ }^{\circ} \mathrm{C}$, a significant band at $3650 \mathrm{~cm}^{-1}$ was detected from degraded poly (BA-a). This band is due to the free $\mathrm{OH}$ group of phenol and it is accompanied by a band at $1180 \mathrm{~cm}^{-1}$, which is due to the $\mathrm{C}-\mathrm{O}$ bond of phenol or substituted phenols. This temperature corresponds to the temperature of the maximum rate of weight loss in the TGA thermogram of poly (BA-a). Thus, the main degradation temperature observed in TGA can be assigned to phenolic cleavage for poly (BA-a).

In short, the TGA and FTIR evolved gas analyses (EGA) indicate that multiple processes are occurring in thermal decomposition of polybenzoxazines. The degradation products are mainly various types of aliphatic or aromatic amines, aliphatic or aromatic Schiff bases, and substituted 
phenolic compounds, depending on the corresponding benzoxazine monomer structure. Based on the TGA and FTIR evolved gas analyses (EGA), the thermal degradation mechanisms of polybenzoxazines have been proposed [12]. Polybenzoxazines have both inter- and intramolecular hydrogen bonding [23] and the presence of the hydrogen bonding is expected to affect the degradation mechanism. For instance, the hydrogen bonding between the $\mathrm{OH}$ group and the $\mathrm{N}$ of the Mannich base results in a conformationally preferred six-membered ring. The thermal cleavage of the Mannich base in the presence of this hydrogen bond is proposed in Scheme 3. The cleavage of the $\mathrm{C}-\mathrm{N}$ bond that is not part of the six-membered ring is more likely to occur because the six-membered ring is energetically more stable. In addition, the cleavage of the $\mathrm{C}-\mathrm{N}$ bond rather than the $\mathrm{C}-\mathrm{C}$ bond from the Mannich base is also expected as the $\mathrm{C}-\mathrm{C}$ bond (bond energy $=82.6 \mathrm{Kcal} / \mathrm{mol}$ ) has higher dissociation energy than the $\mathrm{C}-\mathrm{N}$ bond (bond energy = $72 \mathrm{Kcal} / \mathrm{mol})$ [24]. A Schiff base $(\mathrm{C}=\mathrm{N})$ is formed when the Mannich base is cleaved. So, the next likely cleavage point is the $\mathrm{C}-\mathrm{C}$ bond as the $\mathrm{C}-\mathrm{C}$ bond (bond energy $=82.6 \mathrm{Kcal} / \mathrm{mol}$ ) has a much lower bond energy than a $\mathrm{C}=\mathrm{N}$ bond (bond energy $=147 \mathrm{Kcal} / \mathrm{mol}$ ) [24]. Thus, an aliphatic Schiff base is the degradation product resulting from this cleavage. However, in the case of bisphenol Abased polybenzoxazines, the aromatic Schiff base is also likely to be produced as a degradation product as the bisphenol A backbone is not thermally stable and therefore cleavage of the isopropyl link in the bisphenol A would yield an aromatic Schiff base.

In the aromatic amine-based polybenzoxazine structure, there are two equivalent $\mathrm{C}-\mathrm{N}$ bonds that have equal probability of thermal cleavage in the absence of intramolecular hydrogen bonds. In the case of aliphatic amine-based polybenzoxazines, three $\mathrm{C}-\mathrm{N}$ bonds are present as possible cleavage points. This explains the detection of ammonia as a degradation product for all the aliphatic amine-based polybenzoxazines. The proposed degradation mechanism is shown in Scheme 4. This degradation route provides ammonia and a secondary amine, both of which are detected from the evolved gas analyses of aliphatic amine-based polybenzoxazines. In the case of aromatic amine-based polybenzoxazines, aniline is evolved as a degradation product. It is proposed that the degradation route shown in Scheme 4 is favored at lower temperatures than the degradation route shown in Scheme 3 as the presence of the intramolecular hydrogen bonding has a tendency to stabilize the polybenzoxazine.

\subsection{Evolved Gas Analyses (EGA) of Polybenzoxazines by GC-MS}

The evolved gas analyses (EGA) by using GC-MS were performed for determination of the thermal decomposition products of polybenzoxazines [20]. In GC-MS, the thermal decomposition products are a direct result of either the degradation of the polybenzoxazine or the recombination of the degradation compounds formed during the pyrolysis process. The degradation products of polybenzoxazines identified by GC-MS are grouped into eight categories as follows: benzene derivatives, amines, phenolic compounds, Mannich base compounds, 2,3-benzofuran derivatives, iso-quinoline derivatives, biphenyl compounds, and phenanthridine derivatives. Primary degradation products
SCHEME 3 Proposed Mannich base cleavage in the presence of an intramolecular hydrogen bond.

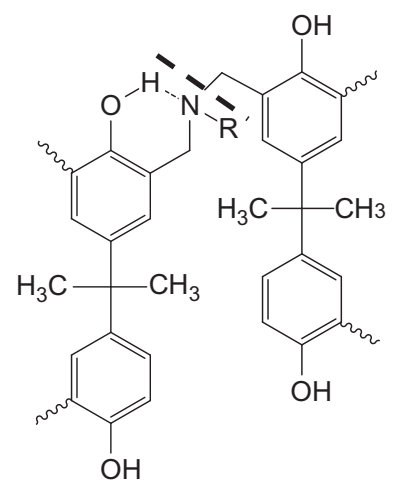<smiles>Cc1cc(C(C)(C)c2cc(C)c(O)c(C)c2)cc(C)c1O</smiles><smiles>[R]N=C</smiles><smiles>Cc1cc(C(C)(C)c2cc(C)c(O)c(C)c2)cc(C)c1O</smiles> 
<smiles>[R]NC=C(C)c1cc(C(C)(C)c2ccc(O)c(C)c2)cc(C)c1O</smiles>

SCHEME 4 Proposed Mannich base cleavage in the absence of a intramolecular hydrogen bond.<smiles>[R]Nc1cc(C(C)(C)c2ccc(O)c(C)c2)cc(C(C)(C)c2cc(C)c(O)c(C(C)(C)c3cc(C)c(O)c(C(C)(C)c4cc(C)c(O)c(C)c4)c3)c2)c1</smiles>

of polybenzoxazines are benzene derivatives, amines, phenolic compounds, Mannich base compounds, while 2,3benzofuran derivatives, iso-quinoline derivatives, biphenyl compounds, and phenanthridine derivatives are secondary degradation products. The compositions of the primary degradation products of polybenzoxazines are given below.

\subsubsection{Benzene Derivatives}

The benzene derivative compounds detected by GC-MS are toluene, dimethylbenzene, and trimethylbenzene. For poly (BA-a) and poly(Ph-a), m-xylene and 1,3,5-trimethylbenzene compounds have the highest intensities. In the case of $\operatorname{poly}(\mathbf{B A}-\mathbf{a}), m$-xylene and 1,3,5-trimethylbenzene are the degradation products that can result directly from the degradation of the polymers as $\operatorname{poly}(\mathbf{B A}-\mathbf{a})$ has a 2,4,6-tri-substituted phenolic structure. However, for poly (Ph-a), the presence of these two degradation products is detected despite the absence of the 1,3,5-trimethylbenzene type structure in the Ph-a monomer. Ph-a has both free ortho and free para positions, which can be subjected to the $\mathrm{C}$-aminoalkylation reaction during the ring-opening polymerization. Therefore, the 2,4,6-tri-substituted phenolic structure is also expected to be present in the network structure of the poly(Ph-a), as shown in Scheme 5.

\subsubsection{Amines}

The major portion of the amines resulting as degradation products for polybenzoxazines is the original amine reactant that is used to obtain benzoxazine monomer. For instance, aniline is one of the major degradation products for both poly(BA-a) and poly(Ph-a). Besides primary amines, substituted amines are also detected as the decomposition products. This suggests that the ortho and para positions of the aniline are also contributing as the reactive side for the polymerization reaction [17].

\subsubsection{Phenolic Compounds}

The majority of the phenolic compounds detected by GC-MS for polybenzoxazines are phenol and substituted phenols such as mono- and dimethylphenol. For poly (BA-a), $p$-iso-propyl phenols were also detected. Phenolic 
SCHEME 5 Proposed structure of $\operatorname{poly}(\mathbf{P h}-\mathbf{a})$.<smiles>Cc1cc(C)c(O)c(CN(Cc2ccc(N(Cc3cccc(CN(Cc4cc(C)cc(C)c4O)c4ccccc4)c3O)Cc3cc(C)cc(CN(Cc4cc(C)cc(C)c4O)c4ccccc4)c3O)cc2)c2ccccc2)c1</smiles>

compounds are the direct result of polybenzoxazine degradation. The studies on the decomposition of the polybenzoxazine model dimers and oligomers have also reported phenolic compounds as one of the major degradation products $[18,21]$.

\subsubsection{Mannich Base Compounds}

The Mannich base compounds detected by GC-MS are obviously direct results of the polybenzoxazine degradation as well. As discussed in the previous section, two fragmentation processes occur simultaneously during the degradation of polybenzoxazines: the cleavages of $\mathrm{C}-\mathrm{N}$ and $\mathrm{C}-\mathrm{C}$ bonds. The degradation mechanism is given in Scheme 6. Depending on the chemical nature of the $\mathrm{R}$ group and the substituent at the nitrogen atom, one of these two processes can predominate over the other. The study on the aliphatic amine-based polybenzoxazine model dimers showed that the size of the amines has a significant effect on the type of cleavage [18]. The benzoxazine dimers with small amines tend to undergo the $\mathrm{C}-\mathrm{C}$ cleavage and form monomers, confirming the occurrence of a reverse Mannich reaction, while the dimers with large amines or aromatic amines tend to favor the $\mathrm{C}-\mathrm{N}$ cleavage, which subsequently causes the formation of Schiff bases.

In brief, the thermal degradation products of polybenzoxazines can be grouped into eight different types of compounds and these compounds can be grouped further into two categories. The first category comprises the primary decomposition products such as benzene derivatives, amines, phenolic compounds, and Mannich base compounds. These compounds are directly obtained from the degradation of the polybenzoxazines itself. The degradation mechanisms involve $\mathrm{C}-\mathrm{N}$ and $\mathrm{C}-\mathrm{C}$ bond cleavages, as discussed above. The proposed network structure of poly (BA-a) and the types of degradation products are illustrated in Scheme 7.
SCHEME 6 Thermal degradation of polybenzoxazine: the cleavages of $\mathrm{C}-\mathrm{N}$ and $\mathrm{C}-\mathrm{C}$ bonds.<smiles>[R]NCc1cc(C)cc(C[NH+]=Cc2cc(C)cc(CC)c2O)c1O</smiles> 
<smiles>Cc1ccc(N(Cc2ccc(N(C)Cc3cc(C(C)(C)c4cc(C)c(O)c(CN(Cc5cc(C)cc(C)c5)c5ccc(C(C)(C)C)cc5)c4)cc(C)c3O)cc2)Cc2cc(C)cc(C)c2O)cc1</smiles>

Primary decomposition products
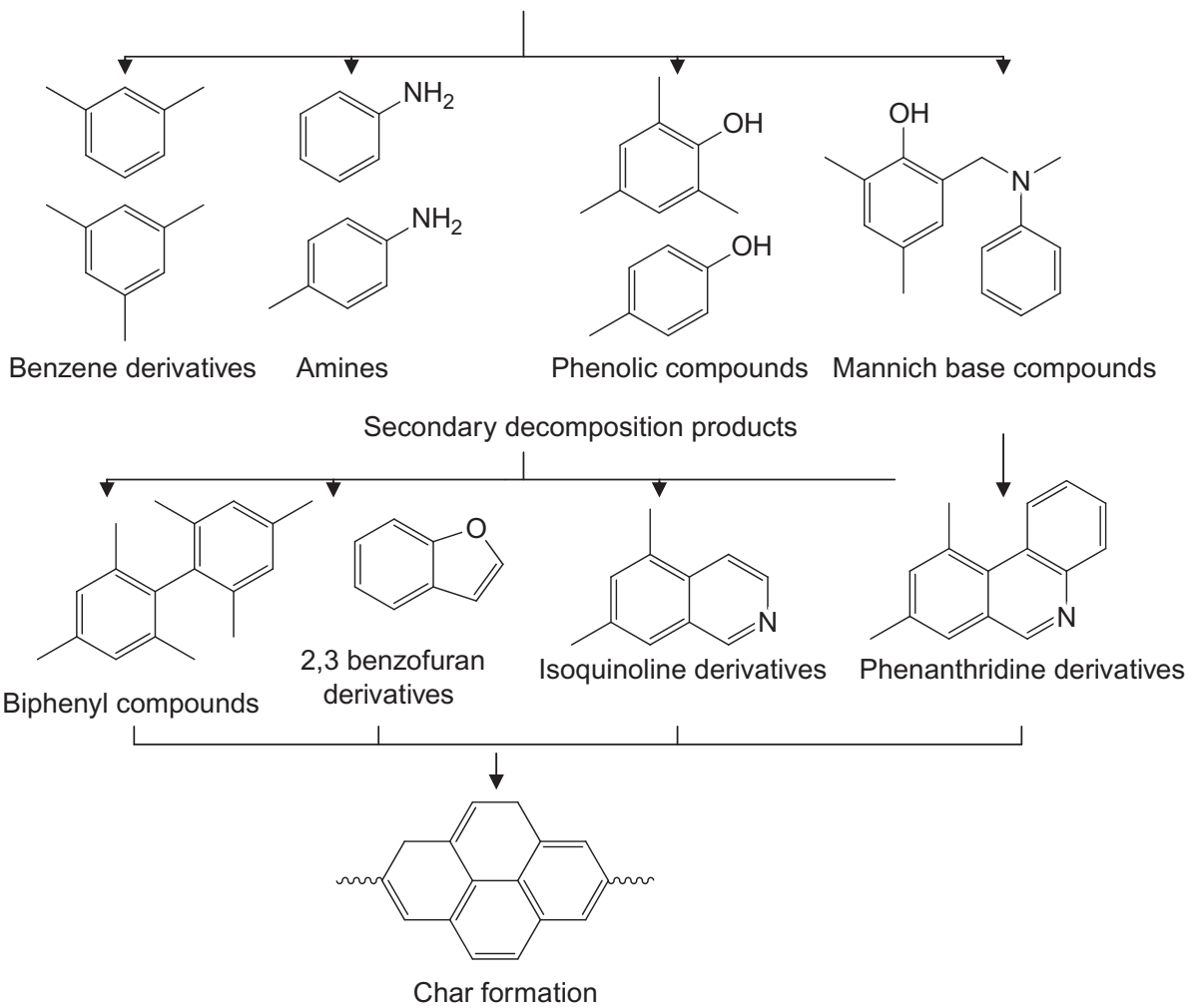

SCHEME 7 The proposed network structure of poly(BA-a) and the resulting degradation products.

\subsection{DP-MS Analysis of Polybenzoxazines}

In the DP-MS technique, mass spectra are recorded continuously during the pyrolysis of the sample at a selected heating rate. The total ion current (the variation of total ion yield as a function of temperature), TIC, curve gives information on thermal characteristics such as thermal stability and temperature ranges where the weight losses occurred, as in the case of the TGA analyses. The presence of more than one peak in the TIC curve points to either a multistep thermal degradation and/or the presence of more than one component with different thermal stabilities. Analyses of pyrolysis mass spectra allow the identification of thermal degradation products. However, the pyrolysis mass spectra of polymers are usually very complex as the thermal degradation products further dissociate in the mass spectrometer during ionization. In addition, all the fragments with the same mass to charge ratio contribute to the intensity of the same peak in the mass spectrum. Thus, in pyrolysis MS analysis, not only the detection of a peak but also the variation of its intensity (single ion pyrograms, evolution profiles) as a function of temperature has particular importance.

The thermal decomposition processes in polybenzoxazines were studied by the application of various techniques [12-19]. Previous work concentrated on the use of 
TGA-FTIR $[12,13]$. With the use of the TGA-GC-MS technique, the identification of volatile products of polybenzoxazine model dimers and oligomers to investigate the thermal degradation mechanisms of polybenzoxazines was proven to be effective [18-21]. Recently, DP-MS analyses of polybenzoxazine based on phenol and methyl amine [22], and aromatic amine-based polynaphthoxazine [25], and polymers involving benzoxazine moieties along the main chain [26] were performed to gain a better understanding of thermal decomposition characteristics. Existence of chains with different structures was suggested as a consequence of the presence of units with varying thermal stabilities.

\subsubsection{Thermal Decomposition of Aliphatic and Aromatic Amine-Based Polybenzoxazines}

DP-MS analyses of typical aliphatic and aromatic aminebased polybenzoxazine analogs, $\operatorname{poly}(\mathbf{P h}-\mathbf{m})$, $\operatorname{poly}(\mathbf{B A}-$ $\mathbf{m})$, poly(Ph-a), and poly(BA-a), were studied to investigate the effect of amine groups on thermal characteristics. The curing programs applied were determined by DSC measurements as $0.5 \mathrm{hr}$ at 160,180 , and $200{ }^{\circ} \mathrm{C}$ and $1.5 \mathrm{~h}$ at $210{ }^{\circ} \mathrm{C}$ for $\operatorname{poly}(\mathbf{P h}-\mathbf{m})$, poly(BA-m), and $\operatorname{poly}(\mathbf{B A}-\mathbf{a})$, and $0.5 \mathrm{~h}$ at 160,170 , and $180^{\circ} \mathrm{C}$ and $1.5 \mathrm{~h}$ at $190{ }^{\circ} \mathrm{C}$ for poly(Ph-a). The total ion current, TIC, curves recorded during the pyrolysis of the polymer samples were quite similar to the corresponding derivative mass loss curves (Figures 5 and 6). The TGA data indicated higher char yields for phenol-based polybenzoxazines, more than $60 \%$ for methyl
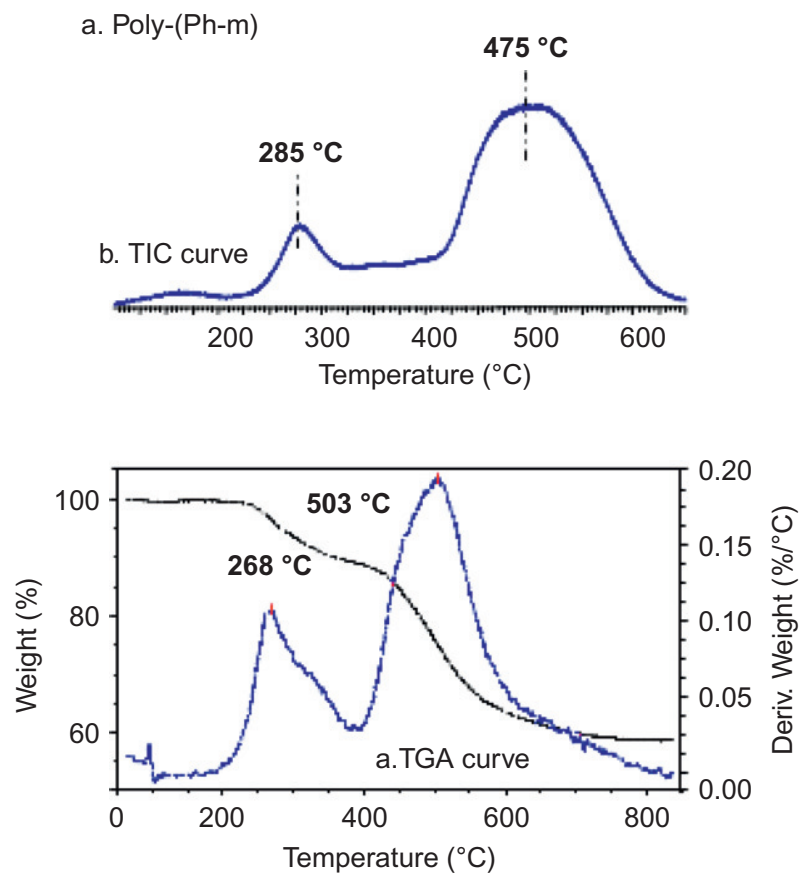

FIGURE 5 The TGA and TIC curves of poly(Ph-m) and poly(BA-m). amine, about $50 \%$ for aniline-based polybenzoxazines, and only about $40 \%$ for the corresponding bisphenol A-based polybenzoxazines. The analysis of pyrolysis mass spectra indicated the evolution of almost similar products for both phenol and bisphenol A-based polybenzoxazines. The differences in the spectra were mainly due to the type of the amine unit present: methyl amine or aniline.

DP-MS analyses revealed that thermal degradation of polybenzoxazines starts with the loss of alkyl amines and diamines in the case of poly(Ph-m) and poly(BA-m), and with the evolution of aniline in the case of $\operatorname{poly}(\mathbf{P h}-\mathbf{a})$ at around $280{ }^{\circ} \mathrm{C}$. Single ion pyrograms of $\mathrm{CH}_{2} \mathrm{NCH}_{2}$ (42 Da) for poly(Ph-m) and poly(BA-m) and those of $\mathrm{C}_{5} \mathrm{H}_{5} \mathrm{NH}_{2}(93 \mathrm{Da})$ for poly(Ph-a) and poly(BA-a) are shown in Figure 7 as representative examples. In the case of $\operatorname{poly}(\mathbf{B A - a})$, the evolution of aniline was detected at higher and broader temperature ranges. The low temperature loss of $\mathrm{N}$-containing fragments was associated with the decomposition of the units generated by the coupling of $\mathrm{CH}_{3} \mathrm{NCH}_{2}$ or $\left(\mathrm{C}_{6} \mathrm{H}_{5}\right) \mathrm{NCH}_{2}$ groups generated by the cleavage of the labile oxazine ring during thermal polymerization. As the evolution of methyl amines and aniline were also detected during the curing process, it was proposed that for poly(BA-a), this step of thermal decomposition was most probably completed during the polymerization of the monomer, BA-a. Emission of alkyl amines was almost totally completed in the first step of the thermal decomposition of methylamine-based polybenzoxazines. On the other hand, aniline evolution was
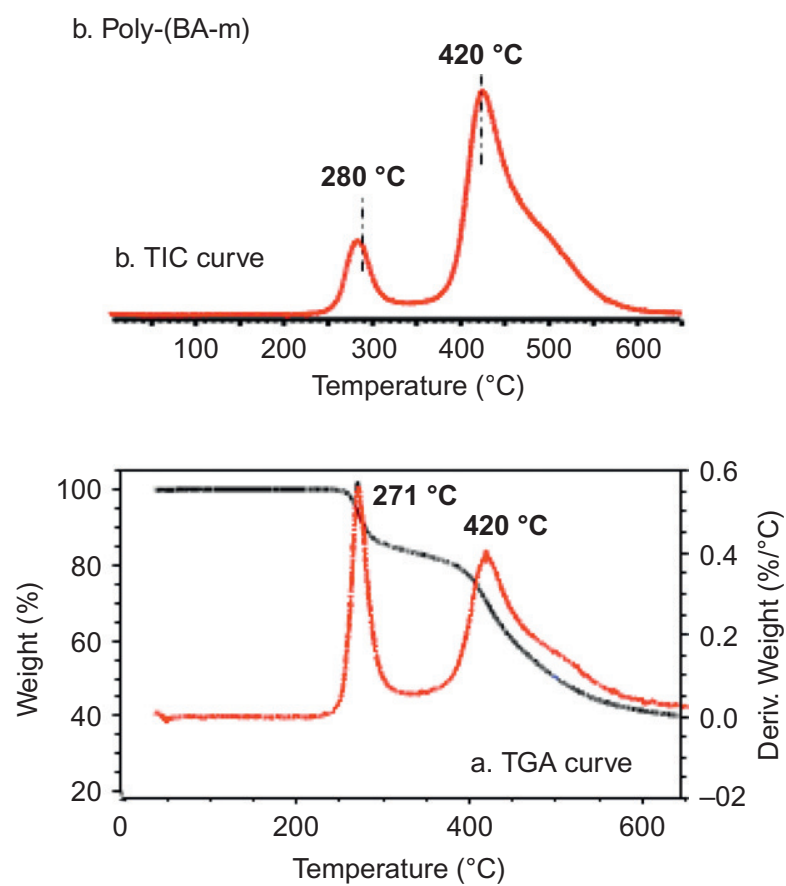

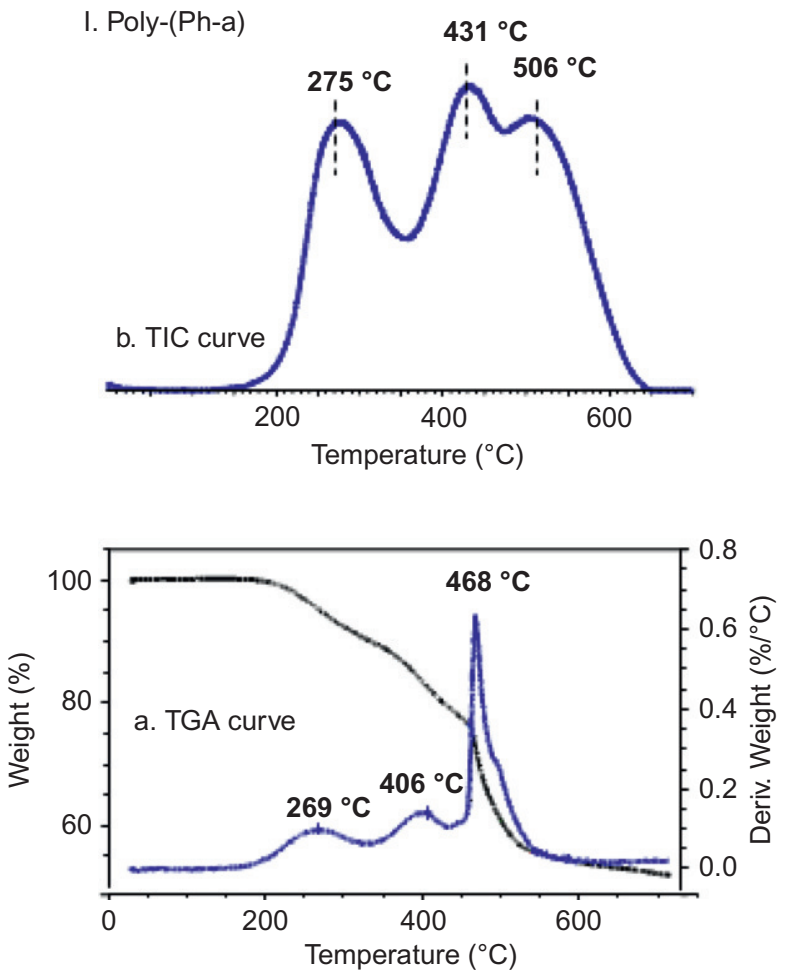

FIGURE 6 The TGA and TIC curves of $\operatorname{poly}(\mathbf{P h}-\mathbf{a})$ and poly(BA-a).

a. $\mathrm{CH}_{2} \mathrm{NCH}_{2}, 42 \mathrm{Da}$
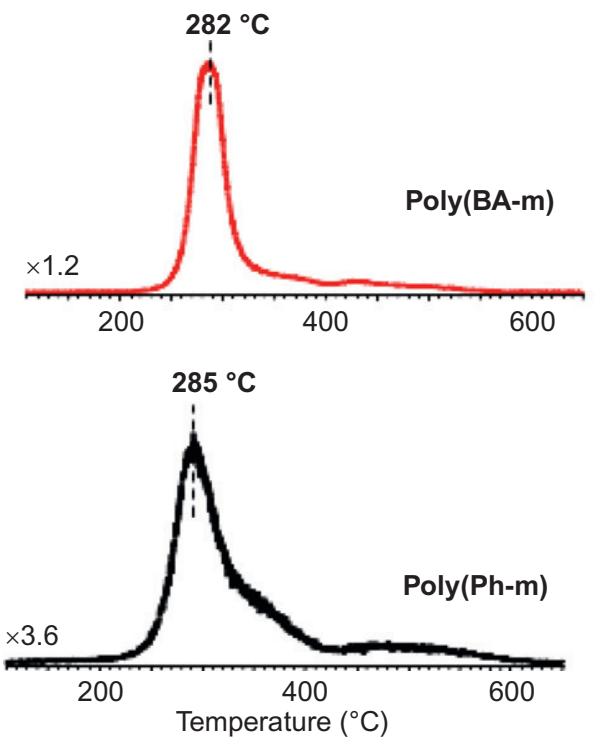
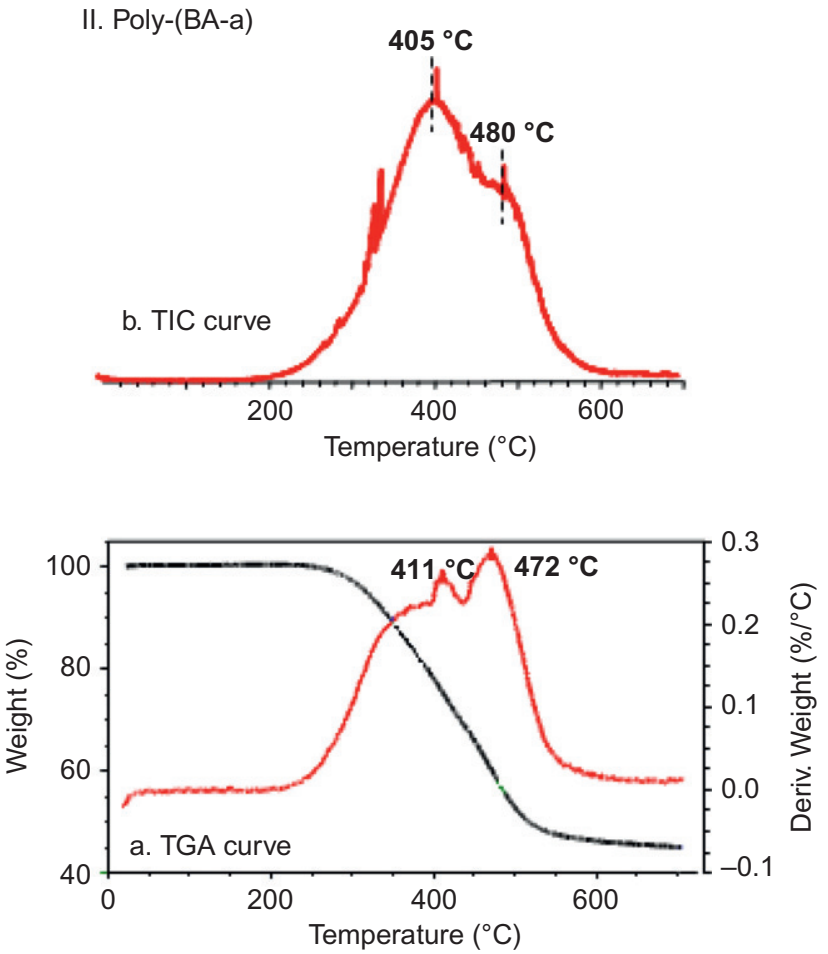

b. $\mathrm{C}_{6} \mathrm{H}_{5} \mathrm{NH}_{2}, 93 \mathrm{Da}$
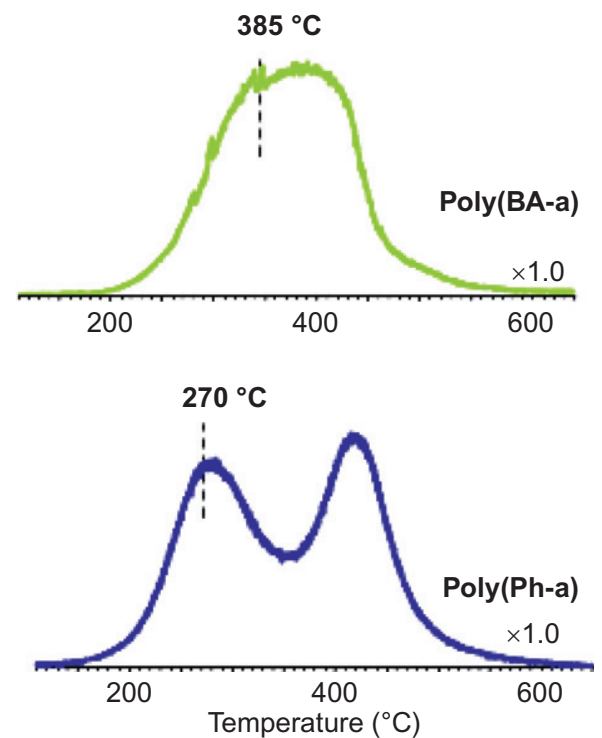

FIGURE 7 Single ion pyrograms of (a) $\mathrm{CH}_{2} \mathrm{NCH}_{2}$ and (b) aniline detected during pyrolysis of phenol and bisphenol A-based polybenzoxazines.

detected over a broad temperature range during the pyrolysis of poly(Ph-a) and poly(BA-a).

Evolution profiles of fragments involving aromatic units showed several peaks and shoulders, revealing the presence of units with different thermal stabilities and hence, the presence of linkages with different structures along the polymer chains. Thermal degradation of the chains generated by the attack of $\mathrm{NCH}_{2}$ groups at ortho and para positions of the phenol ring were expected to occur by random cleavages at $\beta$ carbon to phenol or $\mathrm{N}$ atom, as in case of the EI dissociation of the monomer and dimer. Thus, the fragments such as $\mathrm{HOC}_{6} \mathrm{H}_{4} \mathrm{CH}_{2} \mathrm{NCH}_{3}(136 \mathrm{Da})$ and 
$\mathrm{HOC}_{6} \mathrm{H}_{4} \mathrm{CH}_{2} \mathrm{~N} \quad(150 \mathrm{Da})$ reaching maximum yield at around 474 and $420{ }^{\circ} \mathrm{C}$ for poly(Ph-m) and poly (BA-m), respectively, and the corresponding fragments $\mathrm{HOC}_{6} \mathrm{H}_{4} \mathrm{CH}_{2} \mathrm{NC}_{6} \mathrm{H}_{5}(198 \mathrm{Da})$ and $\mathrm{HOC}_{6} \mathrm{H}_{4} \mathrm{CH}_{2} \mathrm{~N}\left(\mathrm{C}_{6} \mathrm{H}_{5}\right)$ $\mathrm{CH}_{2}(212 \mathrm{Da})$ reaching maximum yield at around 420 and $385{ }^{\circ} \mathrm{C}$ for poly(Ph-a) and poly(BA-a), respectively, were associated with the decomposition of these units. This proposal led to the conclusion that the thermal stability of the chains generated by the attack of $\mathrm{NCH}_{2}$ groups at ortho and para positions of the phenol ring increased in the order $\operatorname{poly}($ BA-a $)<\operatorname{poly}($ BA-m $)<\operatorname{poly}(\mathbf{P h}-a)<\operatorname{Poly}(\mathbf{P h}-m)$.

In Figures 8 and 9, the evolution profiles of $\mathrm{C}_{6} \mathrm{H}_{5} \mathrm{CH}_{2}$ (91 Da), $\mathrm{C}_{6} \mathrm{H}_{5} \mathrm{OH}(94 \mathrm{Da})$, and $\mathrm{HOC}_{6} \mathrm{H}_{4} \mathrm{CH}_{2}$ (107 Da) are shown. Single ion pyrograms of $\mathrm{HOC}_{6} \mathrm{H}_{4} \mathrm{CH}_{2} \mathrm{NCH}_{3}$ (136 Da) for methylamine-based polybenzoxazines and $\mathrm{HOC}_{6} \mathrm{H}_{4} \mathrm{CH}_{2} \mathrm{~N}\left(\mathrm{C}_{6} \mathrm{H}_{5}\right)$ (198 Da) for aniline-based polybenzoxazines are also presented in the figures. The yield of phenyl involving fragments, in the temperature region where the evolution of $\mathrm{N}$ involving fragments was dominant, was significantly low. These findings were explained through the generation of unsaturated units by coupling of the radicals produced upon the loss of amine or aniline units. As an example, single ion pyrograms of $\mathrm{CH}_{2} \mathrm{C}_{6} \mathrm{H}_{4} \mathrm{CH}=\mathrm{CHC}_{6} \mathrm{H}_{4} \mathrm{CH}_{2}$ (206 Da) are included in Figures 8 and 9. Again, an increase was detected in the thermal stability of the units involving vinylene linkage in the order poly(BA-a) $<\operatorname{poly}($ BA-m $)<\operatorname{poly}(\mathbf{P h}-\mathbf{a})<$ poly (Ph-m).
The loss of products, especially during the pyrolysis of poly(Ph-m) and poly(Ph-a) at elevated temperatures, above $500{ }^{\circ} \mathrm{C}$, was associated with the degradation of unsaturated, most probably cross-linked, polymer chains. In the case of poly(Ph-m), the evolution of thermal decomposition products continued at higher temperatures in accordance with the relatively high char yield. On the other hand, for bisphenol A-based polybenzoxazines, the yield of decomposition products in the high temperature ranges was noticeably lower, pointing to a limited extent of cross-linking compared to phenol-based analogs.

The existence of peaks representing additional products involving aromatic units in the pyrolysis mass spectra of aniline-based polybenzoxazines, poly(Ph-a) and poly (BA-a), was explained by the decomposition of the chains generated by the attack of $\mathrm{NCH}_{2}$ groups at ortho and para positions of the aniline ring [18]. These products were maximized at relatively low temperatures, at around 392 and $370{ }^{\circ} \mathrm{C}$, for $\operatorname{poly}(\mathbf{P h}-\mathbf{a})$ and $\operatorname{poly}(\mathbf{B A}-\mathbf{a})$, respectively, pointing to a lower stability compared to the chains generated by the attack of $\mathrm{NCH}_{2}$ groups at ortho and para positions of the phenol ring (Figure 10).

To sum up, DP-MS analysis indicated that thermal decomposition of alkyl amine and aryl amine-based polybenzoxazines starts with the loss of alkyl amines and/or aryl amines. In general, the thermal decomposition of phenolbased polybenzoxazines is completed at higher temperatures compared to the corresponding bisphenol A-based
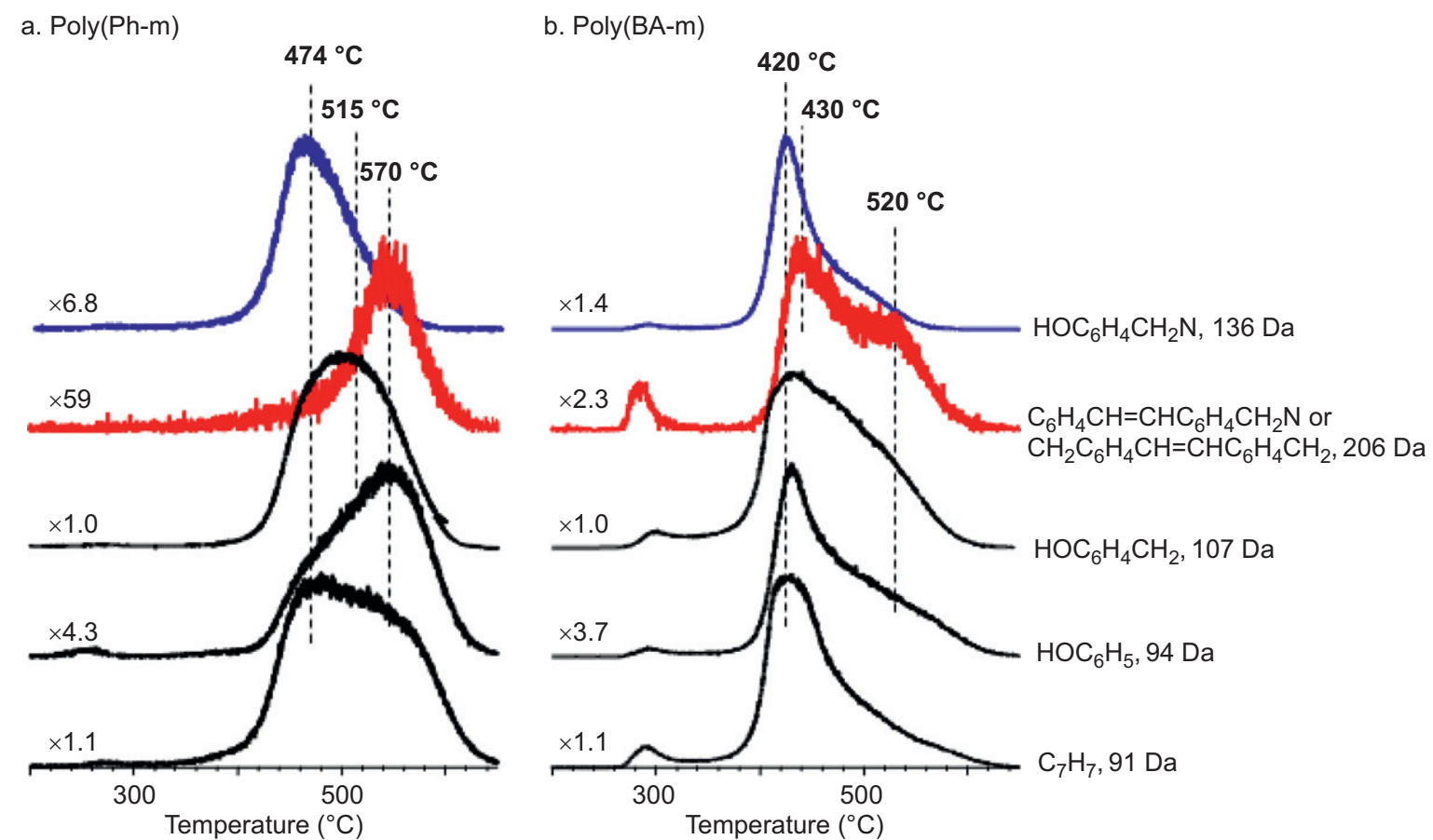

FIGURE 8 Single ion pyrograms of some representative fragments involving aromatic structures detected during the pyrolysis of (a) poly $(\mathbf{P h}-\mathbf{m})$ and (b) $\operatorname{poly}(\mathbf{B A}-\mathbf{m})$. 
a. Poly(Ph-a)

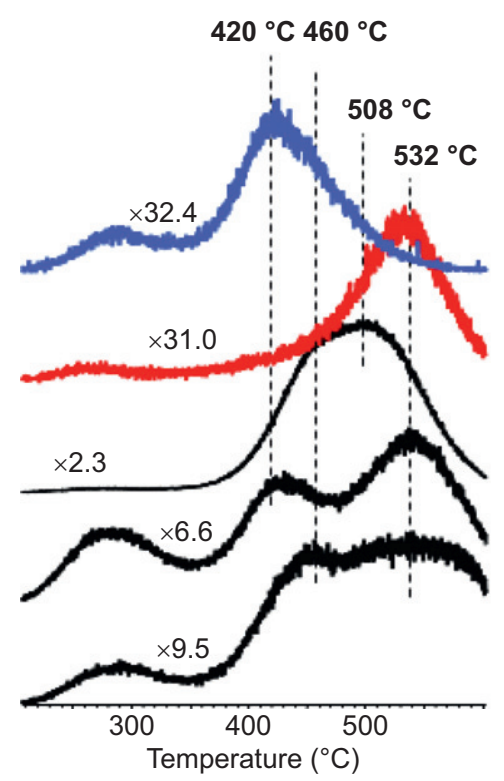

b. Poly(BA-a)

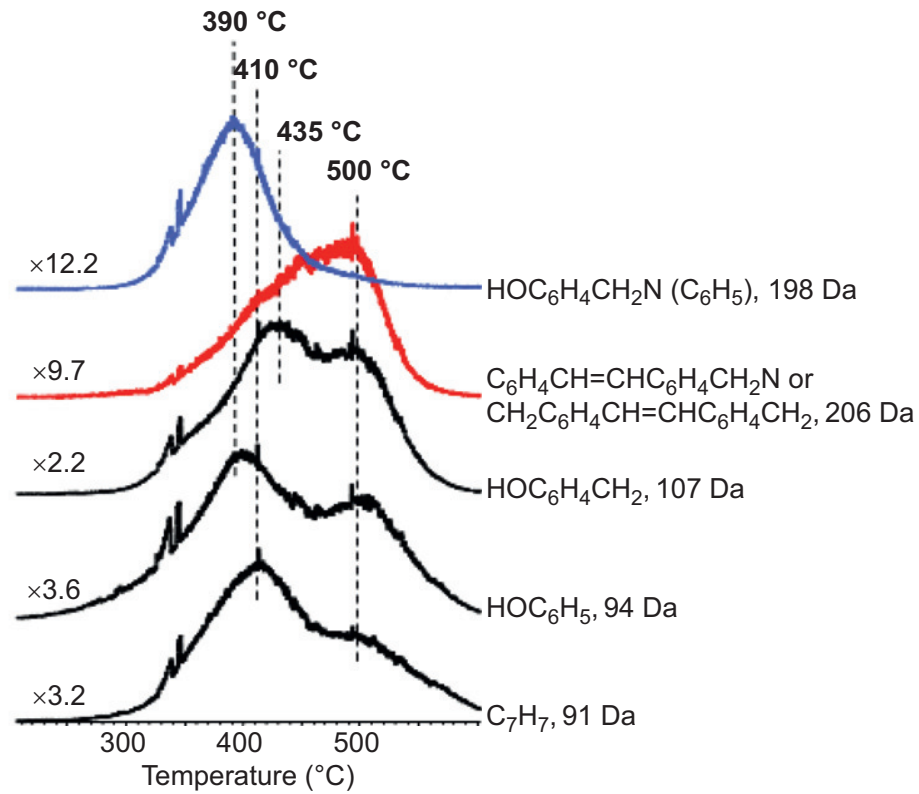

FIGURE 9 Single ion pyrograms of some representative fragments involving aromatic structures detected during the pyrolysis of (a) poly(Ph-a) and (b) $\operatorname{poly}(\mathbf{B A}-\mathbf{a})$.
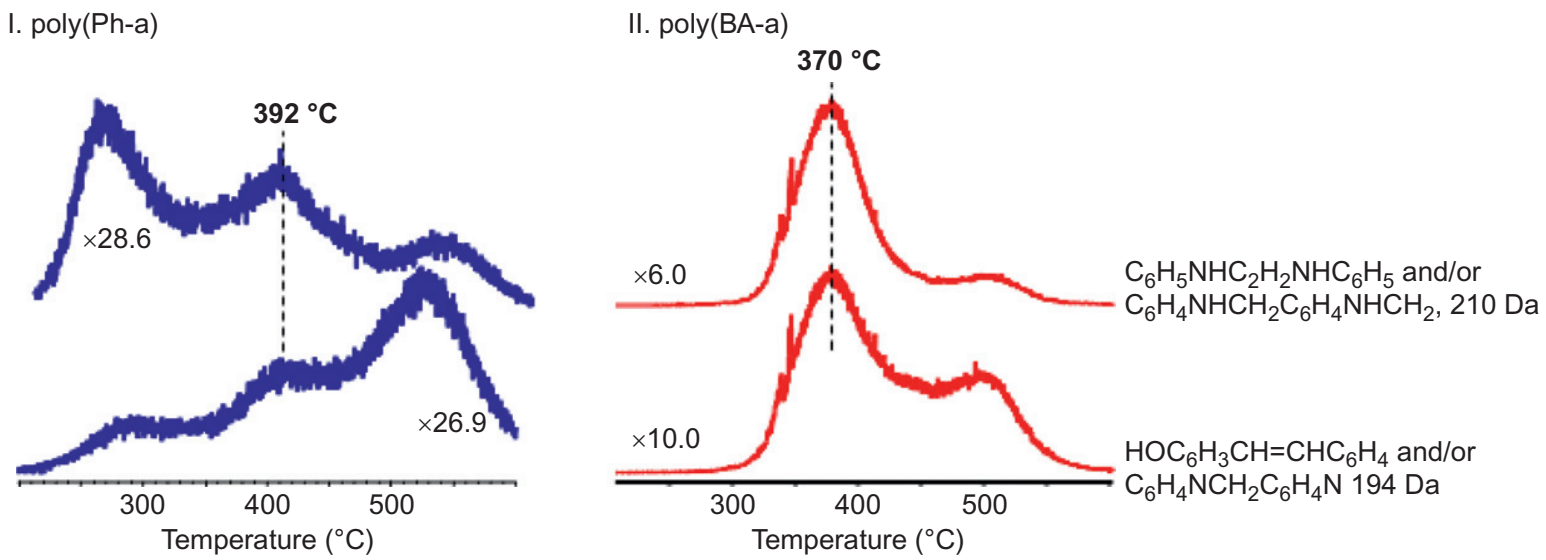

FIGURE 10 Evolution of fragments indicating decomposition of chains generated by attack of $\mathrm{NCH}_{2}$ groups at ortho and para positions of aniline ring.

analogs. This may be due to the presence of relatively weak $\mathrm{C}\left(\mathrm{CH}_{3}\right)_{2}$ linkages joining the two phenyl groups. The presence of very intense peaks due to fragments involving only one phenyl ring pointed to the cleavage of these linkages readily decreasing the overall thermal stability of the bisphenol A-based polybenzoxazines.

\subsubsection{Thermal Decomposition of Furfurylamine-Based Polybenzoxazines}

DP-MS analysis of furfurylamine-based polybenzoxazines $\operatorname{poly}(\mathbf{P h}-\mathbf{f})$ and poly(BA-f) were performed in order to investigate the effect that a polymerizable group substituted to the amine group had on thermal characteristics. In Figure 11, the structures of the benzoxazine monomers thermally polymerized to prepare furfurylamine-based polybenzoxazines are given.

The polybenzoxazines based on furfurylamine and phenol or bisphenol A were prepared by applying two different curing programs. For $\operatorname{poly}\left(\mathbf{P h}-\mathbf{f}_{\mathbf{1}}\right)$ and poly (BA-f $\mathbf{f}_{1}$ ), the last step of the stepwise curing was $190{ }^{\circ} \mathrm{C}$, and for $\operatorname{poly}\left(\mathbf{P h}-\mathbf{f}_{2}\right)$ and $\operatorname{poly}\left(\mathbf{B A}-\mathbf{f}_{2}\right)$, the last step of the stepwise curing was $240{ }^{\circ} \mathrm{C}$. The TIC curves obtained during the pyrolysis of $\operatorname{poly}\left(\mathbf{P h}-\mathbf{f}_{\mathbf{1}}\right)$ and $\operatorname{poly}\left(\mathbf{P h}-\mathbf{f}_{\mathbf{2}}\right)$ are shown in Figure 12. The relative intensity of the low temperature peak, which was maximum at $280{ }^{\circ} \mathrm{C}$, decreased upon 
curing at $240{ }^{\circ} \mathrm{C}$. Furthermore, the broad peak, which was maximum at around $467{ }^{\circ} \mathrm{C}$, became narrower.

The pyrolysis mass spectra of $\operatorname{poly}\left(\mathbf{P h}-\mathbf{f}_{\mathbf{1}}\right)$ recorded around $280{ }^{\circ} \mathrm{C}$ were dominated with peaks due to $\mathrm{CH}_{2} \mathrm{NHCH}_{2} \mathrm{C}_{4} \mathrm{H}_{3} \mathrm{O}$ (110 Da), $\mathrm{CH}_{2} \mathrm{C}_{4} \mathrm{H}_{3} \mathrm{O}$ (81 Da), and $\mathrm{C}_{4} \mathrm{H}_{3} \mathrm{O}(67 \mathrm{Da})$. These products also showed a high temperature peak with a maximum at $461{ }^{\circ} \mathrm{C}$ in their single ion pyrograms (Figure 13a). The evolution of the pyrrole dimer $\left(\mathrm{C}_{4} \mathrm{H}_{2} \mathrm{O}\right)_{2}(132 \mathrm{Da})$ also confirmed the polymerization through the pyrrole units. Peaks due to fragments involving the phenyl ring appeared in the pyrolysis mass spectra recorded above $400{ }^{\circ} \mathrm{C}$. These decomposition products showed almost similar evolution profiles unlike what was observed for poly(Ph-m) and $\operatorname{poly}(\mathbf{P h}-\mathbf{a})$. The only difference was the existence of a high temperature shoulder at around $555^{\circ} \mathrm{C}$ in some of the evolution profiles of phenyl involving fragments such as $\mathrm{C}_{6} \mathrm{H}_{5} \mathrm{OH}(94 \mathrm{Da})$ and $\mathrm{C}_{6} \mathrm{H}_{5} \mathrm{CH}_{2}$ (91 Da) that were associated with the decomposition of cross-linked units, as in the case of poly(Ph-m).

For the sample cured at $240{ }^{\circ} \mathrm{C}$, the low temperature peak was not present in the evolution profiles of furfurylamine involving fragments, indicating that this step<smiles>c1coc(CN2COc3ccccc3C2)c1</smiles>

Ph-f

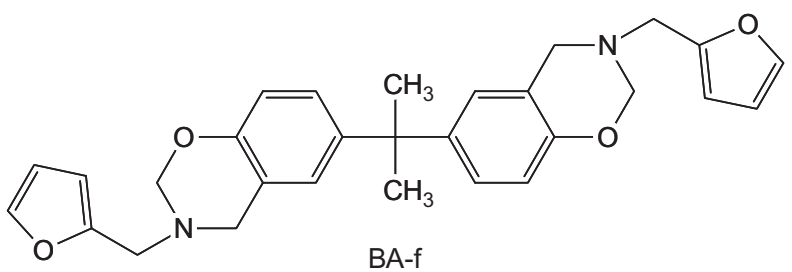

FIGURE 11 Structure of benzoxazine monomers used to prepare furfurylamine-based polybenzoxazines.

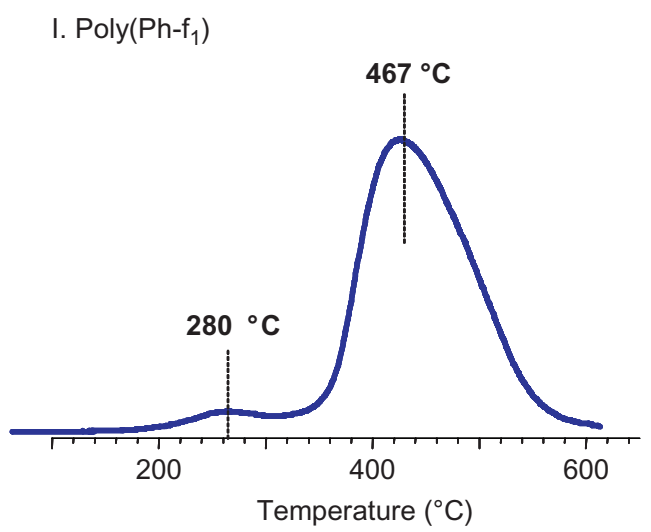

FIGURE 12 TIC curves for $\operatorname{poly}\left(\mathbf{P h}-\mathbf{f}_{1}\right)$ and $\operatorname{poly}\left(\mathbf{P h}-\mathbf{f}_{2}\right)$. of thermal decomposition was completed during the curing process (Figure 13b). Besides the disappearance of peaks at around $280{ }^{\circ} \mathrm{C}$, the trends in the evolution profiles of all the decomposition products were almost identical with the corresponding ones for $\operatorname{poly}\left(\mathbf{P h}-\mathbf{f}_{\mathbf{1}}\right)$, indicating that once the furfurylamine fragments were lost, similar polymer structures were produced.

The thermal decomposition of the corresponding bisphenol A-based polybenzoxazines, $\operatorname{poly}\left(\mathbf{B A}-\mathbf{f}_{\mathbf{1}}\right)$ and poly (BA-f $\mathbf{f}_{2}$ followed almost similar paths. Yet, the thermal stability of $\operatorname{poly}\left(\mathbf{B A}-\mathbf{f}_{\mathbf{1}}\right)$ and $\operatorname{poly}\left(\mathbf{B A}-\mathbf{f}_{2}\right)$ was slightly decreased compared to that of phenol-based analogs (Figure 14). Again, the low temperature peak in the evolution profiles of furfurylamine involving fragments, with a maximum at $275{ }^{\circ} \mathrm{C}$ for $\operatorname{poly}\left(\mathbf{B A}-\mathbf{f}_{\mathbf{1}}\right)$, disappeared in the evolution profiles of the corresponding decomposition products of the $\operatorname{poly}\left(\mathbf{B A}-\mathbf{f}_{2}\right)$ sample cured at $240{ }^{\circ} \mathrm{C}$ (Figure 15). Upon curing at higher temperatures, the peaks in the evolution profiles of phenyl involving fragments sharpened, indicating the generation of a more homogeneous structure. Yet, the relative intensity of the high temperature shoulders also decreased, revealing a decrease in the extent of cross-linking as well.

\subsubsection{Thermal Decomposition of Polysiloxanes and Polyetheresters Containing Benzoxazine Moieties Along the Main Chain}

\subsubsection{Poly(B-ala-co-Tetramethyldisiloxane) (PBTMDS) and Poly(B-ala-co-Dimethylsiloxane) (PBDMS)}

The structures of poly(B-ala-co-tetramethyldisiloxane) (PBTMDS) and poly(B-ala-co-dimethylsiloxane) (PBDMS) are given in Figure 16. The thermal degradation products of polysiloxane-containing benzoxazine units along the main chain can be grouped into three categories: alkyl amines, siloxanes, and fragments involving the aromatic ring [26]. In Figure 17, the evolution profiles of $\mathrm{CH}_{2} \mathrm{NH}_{2}$

II. Poly $\left(P h-f_{2}\right)$

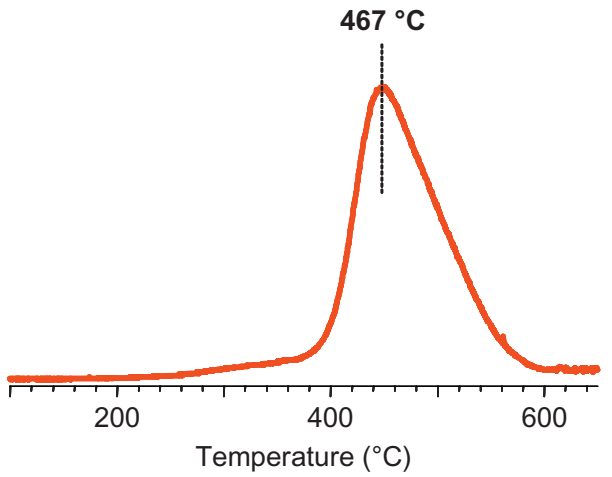




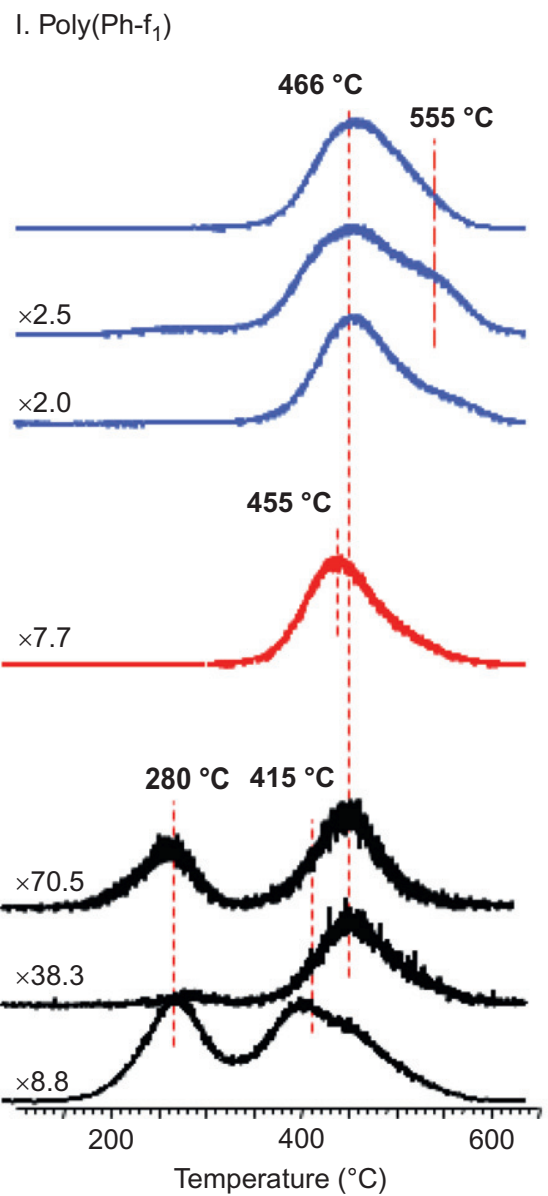

II. $\operatorname{Poly}\left(P h-f_{2}\right)$
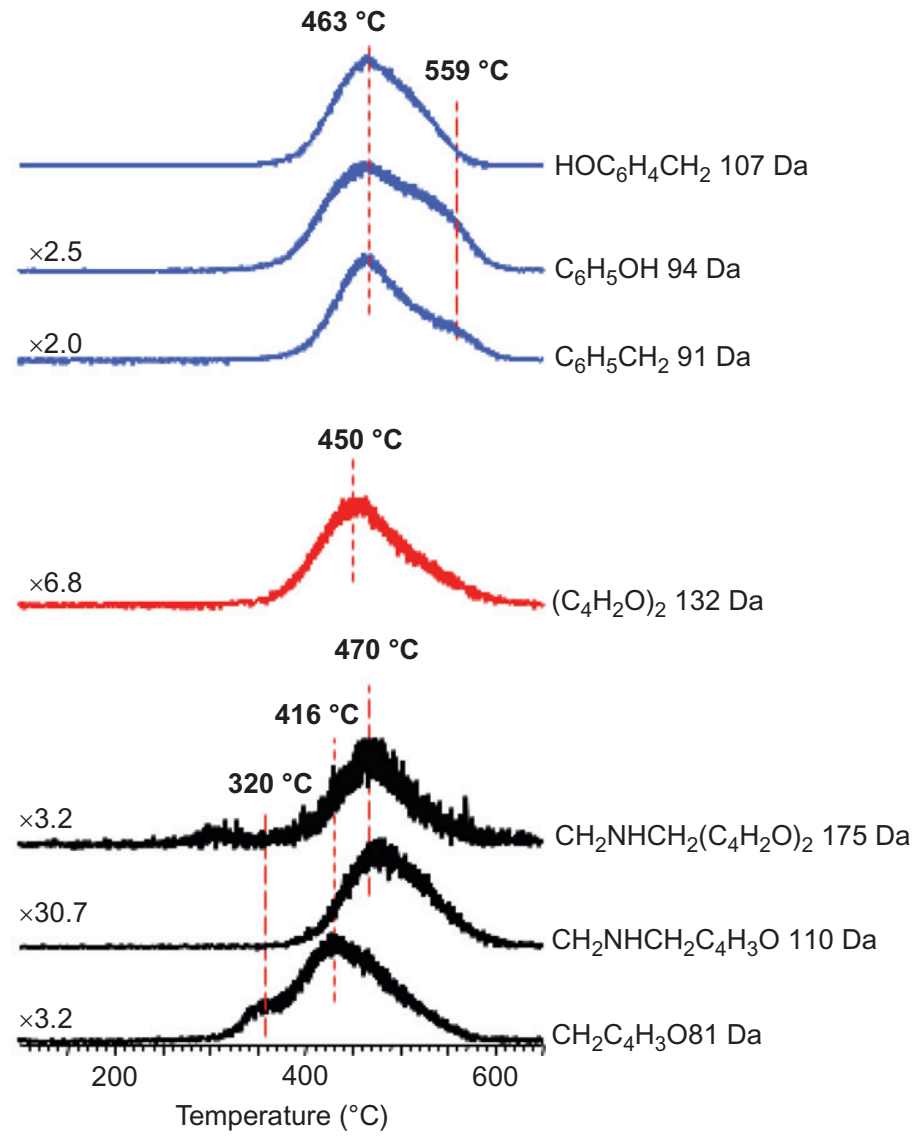

FIGURE 13 Single ion pyrograms of some representative fragments detected during the pyrolysis of (a) poly $\left(\mathbf{P h}-\mathbf{f}_{\mathbf{1}}\right)$ and (b) poly $\left(\mathbf{P h}-\mathbf{f}_{\mathbf{2}}\right)$.

I. Poly $\left(B A-f_{1}\right)$

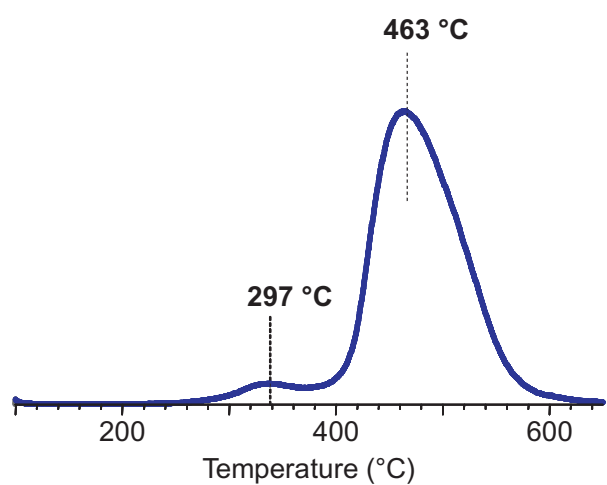

FIGURE 14 TIC curves for $\operatorname{poly}\left(\mathbf{B A}-\mathbf{f}_{1}\right)$ and $\operatorname{poly}\left(\mathbf{B A}-\mathbf{f}_{2}\right)$.

(30 Da), $\mathrm{CH}_{2} \mathrm{NCH}_{2}$ (42 Da) and $\mathrm{CH}_{2} \mathrm{NCH}_{2} \mathrm{CH}_{2}$ or $\mathrm{HNCH}_{2} \mathrm{CH}=\mathrm{CH}_{2} \quad(56 \mathrm{Da}), \quad \mathrm{HSi}\left(\mathrm{CH}_{3}\right)_{2}\left[\mathrm{OSi}\left(\mathrm{CH}_{3}\right)_{2}\right]_{2}$ (207 Da), $\mathrm{HSi}\left(\mathrm{CH}_{3}\right)_{2}\left[\mathrm{OSi}\left(\mathrm{CH}_{3}\right)_{2}\right]_{4}(355 \mathrm{Da}), \mathrm{C}_{6} \mathrm{H}_{5}(77 \mathrm{Da})$, $\mathrm{C}_{6} \mathrm{H}_{5} \mathrm{OH}(94 \mathrm{Da}), \mathrm{C}_{6} \mathrm{H}_{5} \mathrm{CH}_{2} \mathrm{NH}_{2}$ and/or $\mathrm{HOC}_{6} \mathrm{H}_{4} \mathrm{CH}_{2}$ (107 Da), and $\mathrm{C}_{6} \mathrm{H}_{4} \mathrm{C}_{2} \mathrm{H}_{2} \mathrm{C}_{6} \mathrm{H}_{4} \mathrm{CH}_{2}$ and/or $\mathrm{HSi}\left(\mathrm{CH}_{3}\right)[\mathrm{OSi}$ $\left.\left(\mathrm{CH}_{3}\right)_{2}\right]_{2}(192 \mathrm{Da})$ are shown. The presence of intense peaks
II. Poly $\left(B A-f_{2}\right)$

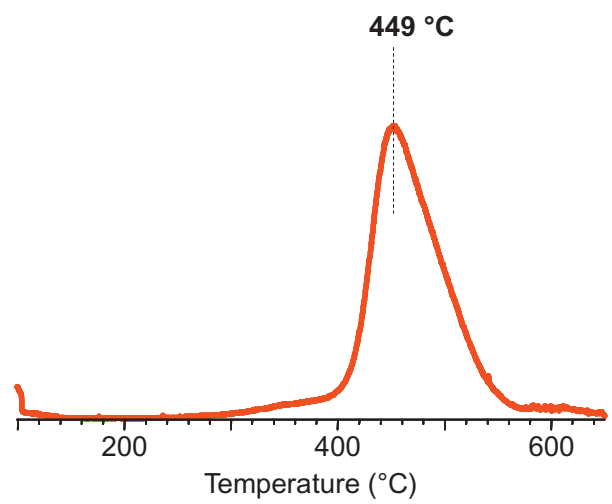

of low mass oligosiloxanes was associated with unwanted polymerization reactions during the synthesis.

The thermal degradation of both PBTMDS and PBDMS was initiated by the evolution of alkyl amines, such as $\mathrm{CH}_{2} \mathrm{NH}_{2}$ (30 Da), $\mathrm{CH}_{2} \mathrm{NCH}_{2}$ (42 Da), and $\mathrm{CH}_{2} \mathrm{NCH}_{2} \mathrm{CH}_{2}$ and/or $\mathrm{HNCH}_{2} \mathrm{CH}=\mathrm{CH}_{2}$ (56 Da), just above $250{ }^{\circ} \mathrm{C}$, 
I. Poly $\left(B A-f_{1}\right)$
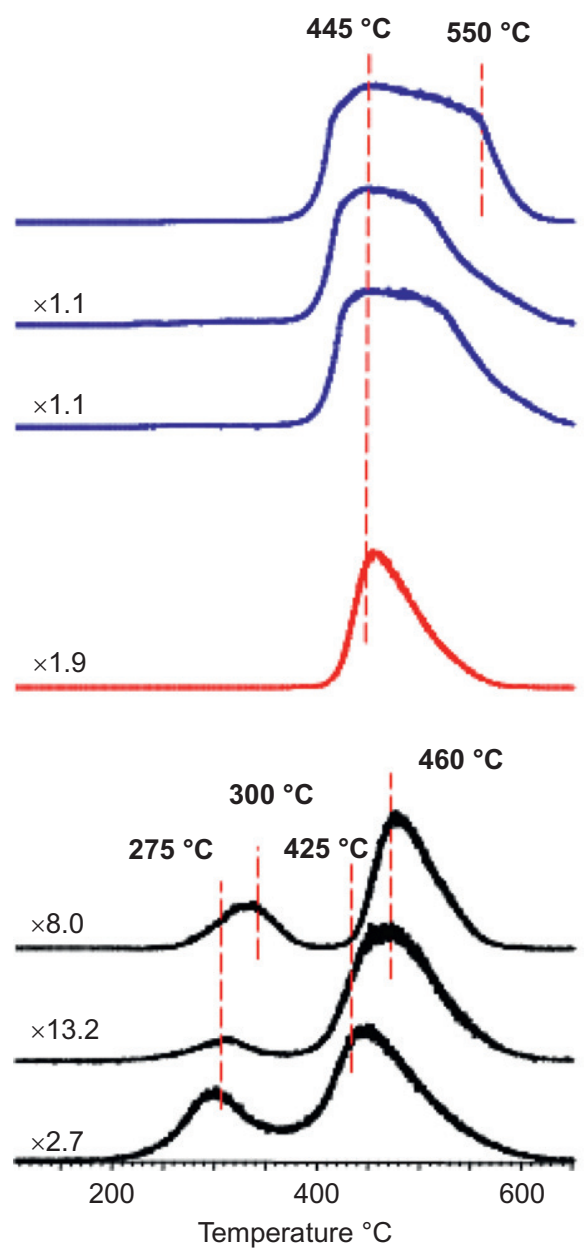

II. $\operatorname{Poly}\left(B A-f_{2}\right)$

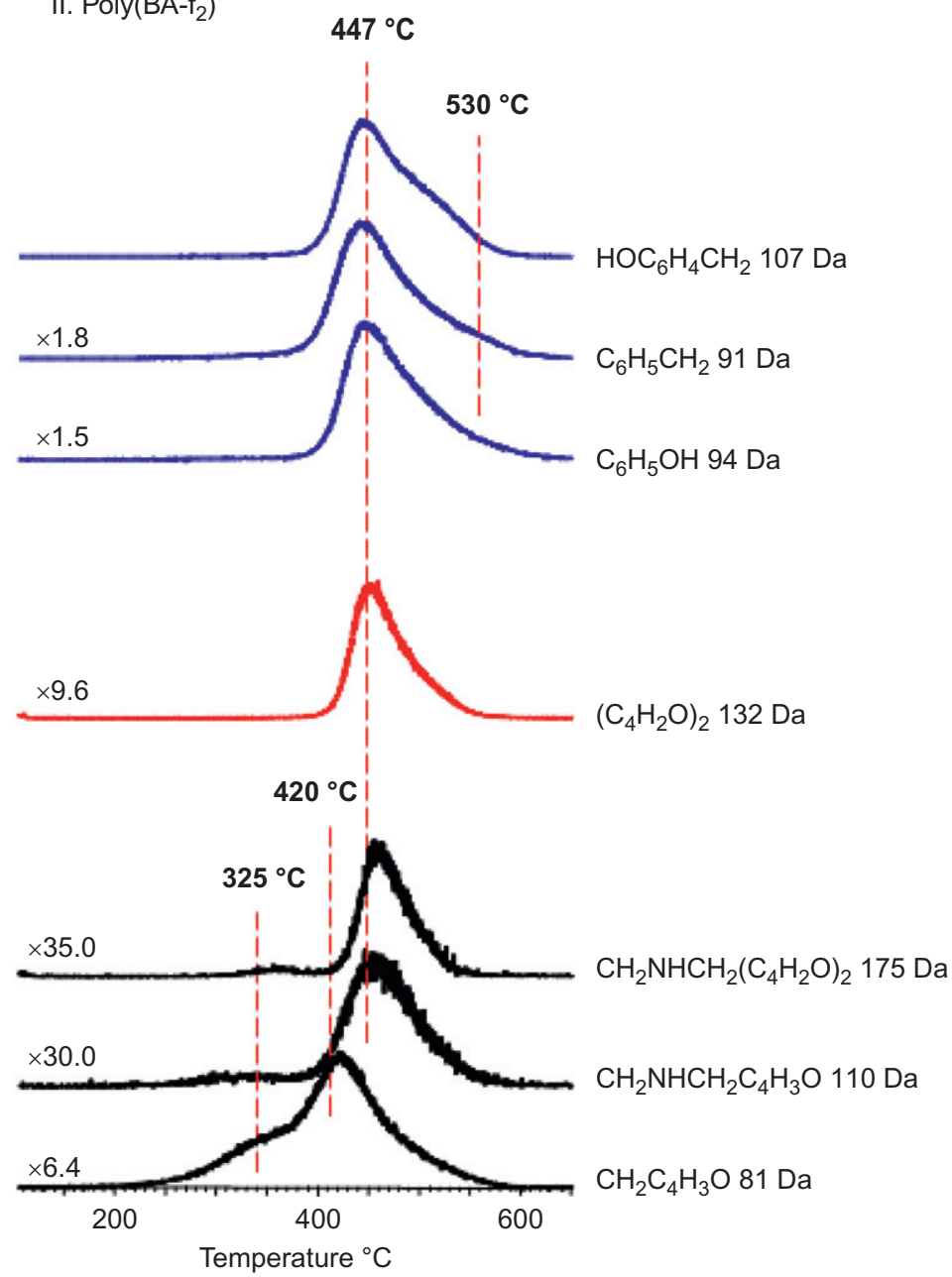

FIGURE 15 Single ion pyrograms of some representative fragments detected during the pyrolysis of (a) $\operatorname{poly}\left(\mathbf{B A}-\mathbf{f}_{\mathbf{1}}\right)$ and (b) poly(PBA-f $\left.\mathbf{f}\right)$.

FIGURE 16 The structures of poly(B-ala-co-tetramethyldisiloxane) (PBTMDS) and poly(B-ala-co-dimethylsiloxane) (PBDMS).
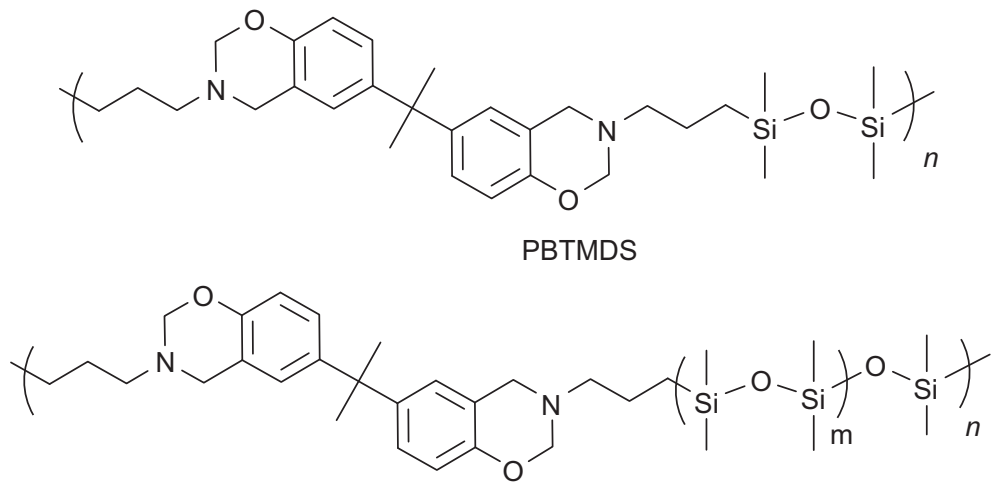

PBDMS

indicating the ready decomposition of the relatively labile oxazine ring. The yield of fragments involving siloxane and phenyl units was extremely low in the region where al$\mathrm{kyl}$ amine evolutions were detected. At around $420^{\circ} \mathrm{C}$, the evolution of alkyl amines, siloxanes, and fragments involving the aromatic ring followed almost similar trends. Hence, thermal decomposition via random cleavages at relatively labile $\mathrm{Si}-\mathrm{C}$ bonds was proposed at around $420{ }^{\circ} \mathrm{C}$. No 

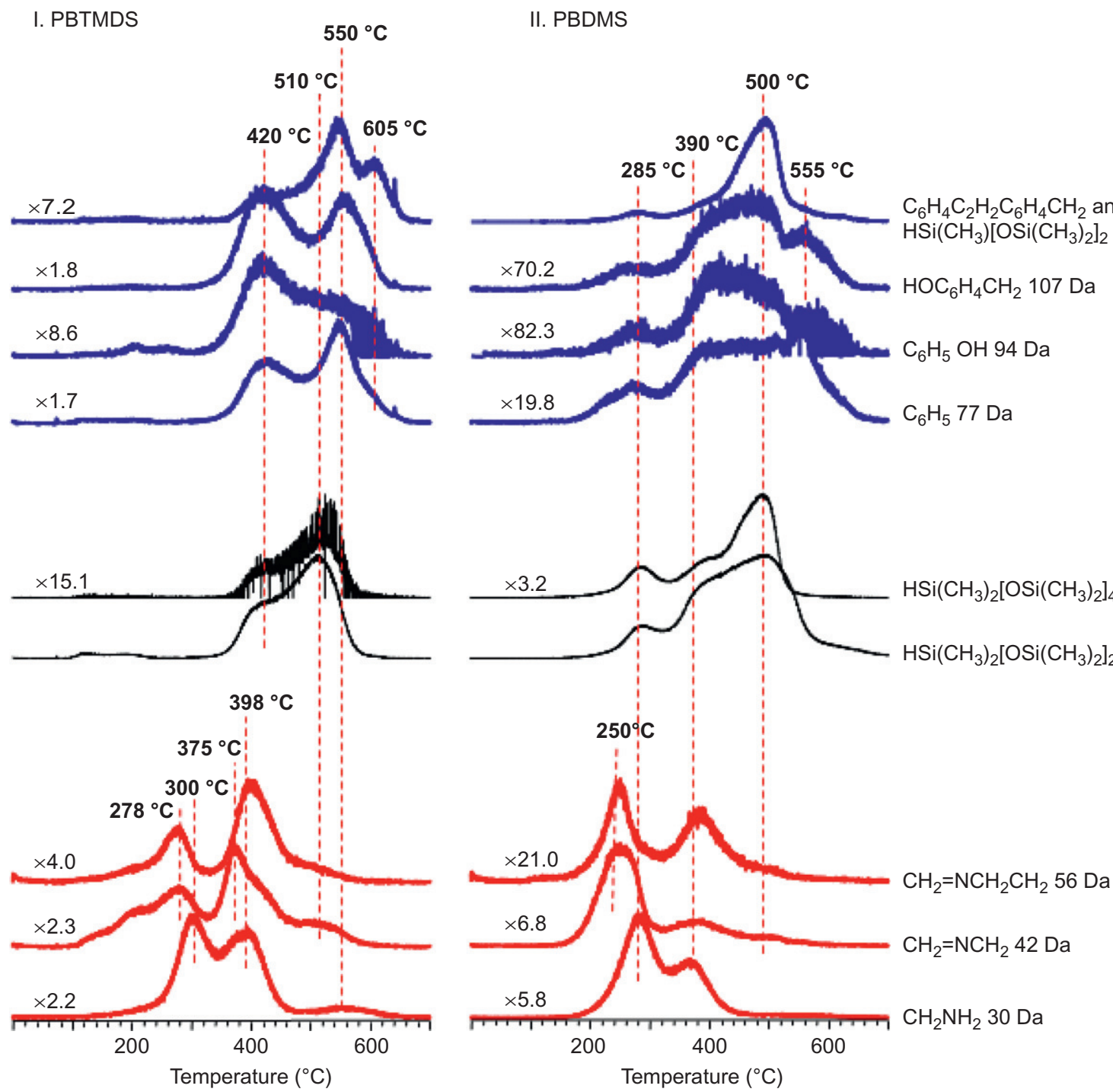

FIGURE 17 Single ion pyrograms of some representative fragments detected during the pyrolysis of (a) PBTMDS and (b) PBDMS.

other similarity existed in the evolution profiles of these three groups of products. The loss of fragments involving aromatic units, such as $\mathrm{C}_{6} \mathrm{H}_{5} \mathrm{OH}$ and $\mathrm{C}_{6} \mathrm{H}_{4} \mathrm{C}_{2} \mathrm{H}_{2} \mathrm{C}_{6} \mathrm{H}_{4} \mathrm{CH}_{2}$, was detected at high temperatures where the evolution of siloxane fragments had almost totally been completed. Thus, generation of polybenzoxazine chains with unsaturated units and/or cross-linked structure upon cleavage of the oxazine ring was proposed. These units decomposed at around 550 and $605{ }^{\circ} \mathrm{C}$, in the temperature range higher than that detected for the similar products during the thermal degradation of polybenzoxazines based on bisphenol A and methylamine $\left(510\right.$ and $\left.550{ }^{\circ} \mathrm{C}\right)$. These findings lead to the conclusion that an increase in thermal stability and in the extent of cross-linking occurred when the benzoxazine moieties were separated by siloxane units.
In the case of PBDMS, the relative yields of both alkyl amines and fragments involving aromatic units were significantly low as expected, as each bisphenol A unit was separated by polysiloxane chains. Three overlapping peaks with maxima at 285,390 , and $500^{\circ} \mathrm{C}$ were detected in the evolution profiles of almost all the thermal degradation products of PBDMS and were associated with degradation via random cleavages at relatively labile $\mathrm{Si}-\mathrm{C}$ bonds (Figure 17). The broad evolution profiles with several overlapping peaks were associated with the polydispersity of the sample and the presence of low mass oligomers.

Two noticeable differences were the low temperature loss of alkyl amines and the high temperature evolutions of fragments involving aromatic units. Weak peaks with maxima at 555 and $605{ }^{\circ} \mathrm{C}$ were also observed in the 
evolution profiles of fragments involving aromatic units, yet their relative intensities were significantly weak compared to what was recorded for PBTMDS. Hence, it can be concluded that as siloxane decomposition took place, loss of bisphenol A units also took place and the extent of polymerization by the opening of the oxazine ring and cross-linking was significantly lowered when longer polysiloxanes were used instead of oligosiloxanes.

\subsubsection{Polyetherester Containing Benzoxazine} Moiety (PEE-BT)

The structure of polyetherester-containing benzoxazine moiety (PEE-BT) is given in Figure 18. Evolution of alkyl amines, such as $\mathrm{CH}_{2} \mathrm{NH}_{2}(30 \mathrm{Da})$ and $\mathrm{CH}_{2}=\mathrm{NCH}_{2} \mathrm{CH}_{2}$ $(56 \mathrm{Da})$, was also detected at the early stages of pyrolysis of PEE-BT, at around 278 and $297{ }^{\circ} \mathrm{C}$ (Figure 19). These

FIGURE 18 The structure of polyether estercontaining benzoxazine moiety (PEE-BT).<smiles>[R]C(C(=O)OCCOCCN1COc2ccc(C(C)(C)c3ccc4c(c3)CN(CCOCCOC(C)(C)C)CO4)cc2C1)C(C)(C)C</smiles>

FIGURE 19 Single ion pyrograms of some representative fragments detected during the pyrolysis of PEE-BT.

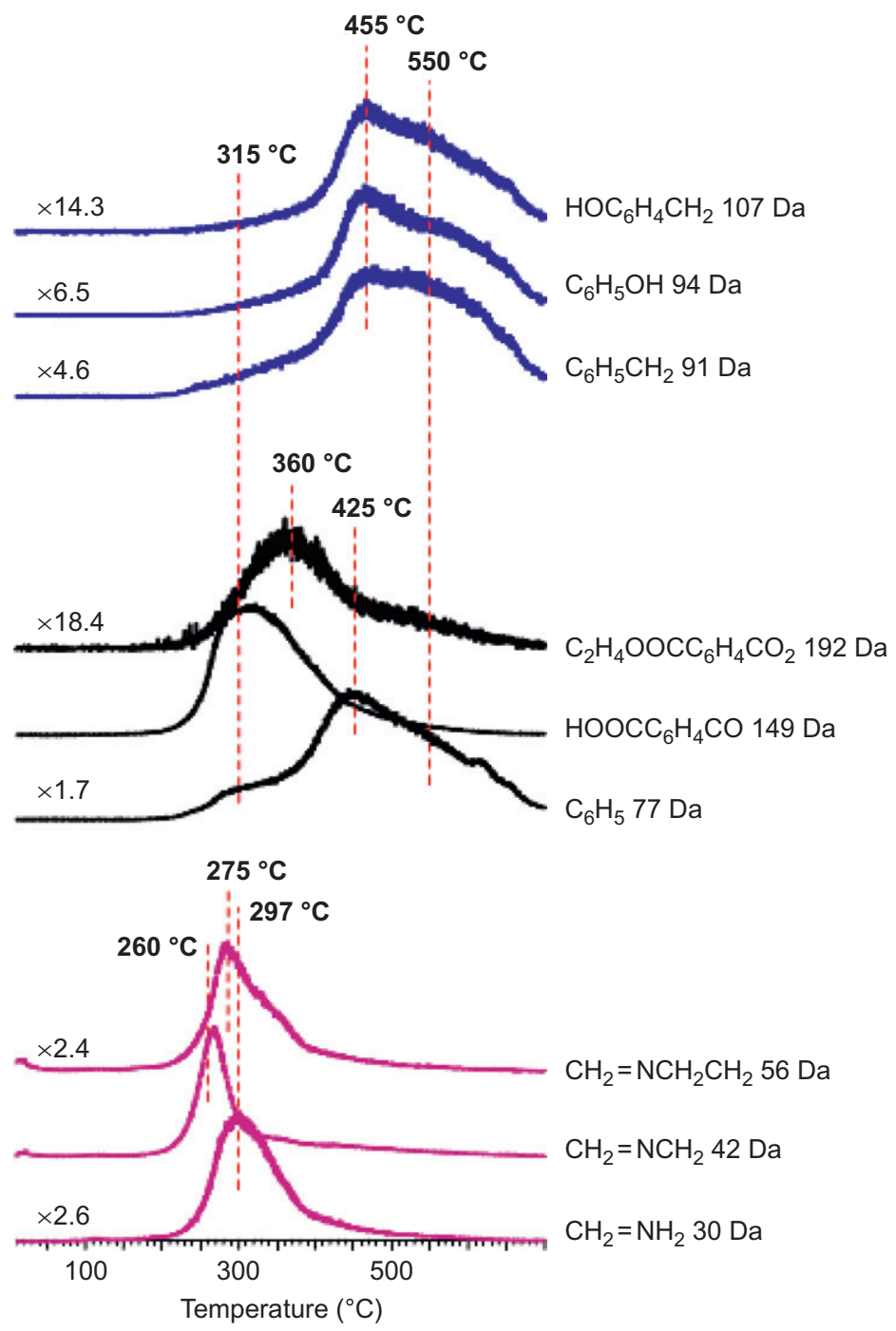


values are very close to the corresponding values recorded for poly(Ph-m), poly(BA-m), PBTMDS, and PBDMS. It is clear that the decomposition of the oxazine ring was not affected by the nature of the chains connecting the bisphenol A units or by the unit substituted on $\mathrm{N}$.

Decomposition of terephthaloyl groups was detected at around 315 and $360{ }^{\circ} \mathrm{C}$. The yield of products generated by the cleavage of $-\mathrm{CH}_{2}-\mathrm{OC}=\mathrm{OR}$ bonds was maximized at lower temperatures compared to those generated by the cleavage of $-\mathrm{CH}_{2}-\mathrm{O}-\mathrm{CH}_{2}-$ groups. As in the case for PBTMDS, the products involving aromatic units were maximized at around $425^{\circ} \mathrm{C}$. The shoulder in the evolution profiles of these products at around $315^{\circ} \mathrm{C}$ was attributed to the degradation of etherester groups yielding the fragments with the same $\mathrm{m} / \mathrm{z}$ values, i.e., $\mathrm{C}_{6} \mathrm{H}_{5} \mathrm{CO}$ and $\mathrm{C}_{6} \mathrm{H}_{4} \mathrm{CH}_{2} \mathrm{NH}$ (105 Da). These products showed high temperature tails in their evolution profiles. Products that can only be generated by degradation of bisphenol A units showed a maximum at $455{ }^{\circ} \mathrm{C}$ and a high temperature shoulder around $550{ }^{\circ} \mathrm{C}$, at noticeably lower temperatures than the corresponding values detected for PBTMDS. The lower thermal stability was associated with the lower thermal stability of the polyether ester chains compared to polysiloxanes. Hence, it was concluded that thermal stability and extent of cross-linking enhanced when the benzoxazine moieties were separated by thermally more stable units such as siloxanes. However, when the siloxane chain units were long, the possibility of polybenzoxazine growth decreased significantly.

\section{CONCLUSIONS}

Thermal decomposition of aliphatic amine-based polybenzoxazines starts with the loss of $\mathrm{CH}_{2}-\mathrm{NCH}_{2} \mathrm{R}$ groups by cleavage at $\beta$ carbon to $\mathrm{N}$ atom at around $280{ }^{\circ} \mathrm{C}$. The identity of the $\mathrm{R}$ group does not have any significant effect on the loss of alkyl amines in accordance with expectations as dependence of $\mathrm{CH}_{2}-\mathrm{N}\left(\mathrm{CH}_{2} \mathrm{R}\right) \mathrm{CH}_{2}$ bond energy on the $\mathrm{R}$ group should be negligible. Polymers involving benzoxazine moieties connect to $\mathrm{N}$ of the oxazine rings by methylene, and $\mathrm{CH}_{2}$ groups also lose $\mathrm{CH}_{2} \mathrm{NCH}_{2}-$ groups following the cleavage of oxazine rings. On the other hand, evolution of aniline is the first step of thermal degradation in the case of aniline-based polybenzoxazine.

Decomposition of products involving phenyl groups evolved above $400{ }^{\circ} \mathrm{C}$ over a broad temperature range, indicating the presence of units with different thermal stabilities and, hence, structures. Thermal degradation of the chains generated by the attack of $\mathrm{CH}_{2}\left(\mathrm{RCH}_{2}\right) \mathrm{NCH}_{2}-$ groups on ortho and para positions of the phenyl ring occurs at around $400{ }^{\circ} \mathrm{C}$. The thermal stability of these chains is lower than that of the chains involving vinylene linkages. Vinylene linkages combining two phenoyl or bisphenoyl groups are produced by coupling reactions upon cleavage of the oxazine ring during curing or upon the loss of alkyl amines or aniline during thermal degradation. These units can further cross-link and increase the char yield during heating.

Although the $\mathrm{R}$ group substituted to $\mathrm{NCH}_{2}-$ does not have any significant effect on cleavage at $\beta$ carbon to $\mathrm{N}$ atom, it controls the efficiency of coupling reactions. The presence of a bulky group decreases the probability of coupling reactions during the polymerization and/or thermal decomposition, thus decreasing the extent of cross-linking. The high char yield of methylamine-based polybenzoxazines supports these proposals. On the other hand, the presence of a polymerizable $\mathrm{R}$ group increases the thermal stability of the chains generated by the attack of $\mathrm{RCH}_{2} \mathrm{NCH}_{2}$ - groups on ortho and para positions of the phenyl ring.

In general, the thermal decomposition of phenol-based polybenzoxazines is completed at higher temperatures than the corresponding bisphenol A-based analogs. This may be due to the presence of relatively weak $\mathrm{C}\left(\mathrm{CH}_{3}\right)_{2}$ linkages joining the two phenyl groups. Successful attempts at the polymerization of benzoxazine moieties along polymer chains increased thermal stability and the extent of cross-linking. The increase in thermal stability depends on the stability of the polymer chains separating the benzoxazine moieties. However, when the polymer chain units are long, the possibility of polybenzoxazine growth decreases significantly.

\section{REFERENCES}

[1] C.A. Wilkie, TGA/FTIR: an extremely useful technique for studying polymer degradation, Polym. Degrad. Stabil. 66 (3) (1999) 301-306.

[2] F. Hoffmann, R. Riesen, J. Foreman, Characterization of thermal stability and reaction products by means of TGA-FTIR coupling, Am. Lab. 32 (1) (2000) 13.

[3] K.G.H. Raemaekers, J.C.J. Bart, Applications of simultaneous thermogravimetry-mass spectrometry in polymer analysis, Thermochim. Acta 295 (1997) 1-58.

[4] K.L. Sobeih, M. Baron, J. Gonzalez-Rodriguez, Recent trends and developments in pyrolysis-gas chromatography, J. Chromatog. A 1186 (2008) 51-66.

[5] S. Tsuge, H. Ohtani, Structural characterization of polymeric materials by pyrolysis-GC/MS, Polym. Degrad. Stabil. 58 (1-2) (1997) 109-130.

[6] M. Blazsó, Recent trends in analytical and applied pyrolysis of polymers, J. Anal. Appl. Pyrol. 39 (1997) 1-25.

[7] M. Herrera, G. Matuschek, A. Kettrup, Fast identification of polymer additives by pyrolysis-gas chromatography/mass spectrometry, J. Anal. Appl. Pyrol. 70 (1) (2003) 35-42.

[8] M. Blazsó, In situ modification of pyrolysis products of macromolecules in an analytical pyrolyser, J. Anal. Appl. Pyrol. 74 (1-2) (2005) 344-435.

[9] Z. Parsi, T. Górecki, J. Poerschmann, Advances in non-discriminating pyrolysis, J. Anal. Appl. Pyrol. 74 (2005) 11-18. 
[10] K. Qian, W.E. Killinger, M. Casey, Rapid polymer identification by in-source direct pyrolysis mass spectrometry and library searching techniques, Anal. Chem. 68 (1996) 1019-1027.

[11] G. Montaudo, Direct mass spectrometry of polymers, Br. Polym. J. 18 (4) (1986) 231-235.

[12] H.Y. Low, H. Ishida, Mechanistic study on the thermal decomposition of polybenzoxazines: effects of aliphatic amines, J. Polym. Sci. B Polym. Phys. 36 (1998) 1935-1946.

[13] H.Y. Low, H. Ishida, Structural effects of phenols on the thermal and thermo-oxidative degradation of polybenzoxazines, Polymer 40 (15) (1999) 4365-4376.

[14] H.Y. Low, H. Ishida, An investigation of the thermal and thermooxidative degradation of polybenzoxazines with a reactive functional group, J. Polym. Sci. B Polym. Phys. 37 (1999) 647-659.

[15] Z. Brunovska, H. Ishida, Thermal study on the copolymers of phthalonitrile and phenylnitrile-functional benzoxazines, J. Appl. Polym. Sci. 73 (1999) 2937-2949.

[16] H.J. Kim, Z. Brunovska, H. Ishida, Synthesis and thermal characterization of polybenzoxazines based on acetylene-functional monomers, Polymer 40 (23) (1999) 6565-6573.

[17] H. Ishida, D.P. Sanders, Improved thermal and mechanical properties of polybenzoxazines based on alkyl-substituted aromatic amines, J. Polym. Sci. B Polym. Phys. 38 (2000) 3289-3301.

[18] K. Hemvichian, A. Laobuthee, S. Chirachanchai, H. Ishida, Thermal decomposition processes in polybenzoxazine model dimers investigated by TGA-FTIR and GC-MS, Polym. Degrad. Stabil. 76 (2002) 1-15.
[19] H.Y. Low, H. Ishida, Improved thermal stability of polybenzoxazines by transition metals, Polym. Degrad. Stabil. 91 (2006) 805-815.

[20] K. Hemvichian, H. Ishida, Thermal decomposition processes in aromatic amine-based polybenzoxazines investigated by TGA and GC-MS, Polymer 43 (2002) 4391-4402.

[21] K. Hemvichian, H.D. Kim, H. Ishida, Identification of volatile products and determination of thermal degradation mechanisms of polybenzoxazine model oligomers by GC-MS, Polym. Degrad. Stabil. 87 (2005) 213-224.

[22] S. Bagherifam, T. Uyar, H. Ishida, J. Hacaloglu, The use of pyrolysis mass spectrometry to investigate polymerization and degradation processes of methyl amine-based benzoxazine, Polym. Test. 29 (4) (2010) 520-526.

[23] H.D. Kim, H. Ishida, A study on hydrogen bonding in controlledstructure benzoxazine model oligomers, Macromol. Symp. 195 (2003) 123-140.

[24] L. Pauling, Chemical Bonds, in: Cornell University Press, New York, 1960 , p. 85.

[25] T. Uyar, Z. Koyuncu, H. Ishida, J. Hacaloglu, Polymerisation and degradation of an aromatic amine-based naphthoxazine, Polym. Degrad. Stabil. 93 (12) (2008) 2096-2103.

[26] S. Bagherifam, B. Kiskan, B. Aydogan, Y. Yagci, J. Hacaloglu, Thermal degradation of polysiloxane and polyetherester containing benzoxazine moieties in the main chain. J. Anal. Appl. Pyrol. 90 (2011) 155-163. 